Research Article

\title{
Comparative Analysis of Longitudinal and Transverse Vibration Characteristics of Ocean Mining Pipe
}

\author{
Qiang Liu and Lin-jing Xiao \\ College of Mechanical \& Electronic Engineering, Shandong University of Science and Technology, Qingdao 266590, China \\ Correspondence should be addressed to Lin-jing Xiao; skdjdxy17@163.com
}

Received 28 January 2021; Accepted 28 May 2021; Published 11 June 2021

Academic Editor: Zengshun Chen

Copyright (c) 2021 Qiang Liu and Lin-jing Xiao. This is an open access article distributed under the Creative Commons Attribution License, which permits unrestricted use, distribution, and reproduction in any medium, provided the original work is properly cited.

\begin{abstract}
In this paper, the $5000 \mathrm{~m}$ mining pipe is taken as the research object, and the transverse and longitudinal vibration laws of the pipe under different working conditions are analyzed. Based on the finite element method (FEM), the pipe is discretized and calculated by the Wilson- $\theta$ integral method; finally, the corresponding vibration laws of the mining pipe are obtained. The research shows that the mining pipe vibration responses are irregular motion, with the obvious oscillation phenomenon, and the overall vibration trend decreases first and then increases from the top to the bottom; the maximum vibration response occurs at the pipe top. Under the same working conditions, increasing the towing velocity will decrease the overall longitudinal vibration amplitude and increase the overall transverse vibration amplitude. While the ore bin weight will increase the longitudinal vibration amplitude and decrease the transverse vibration amplitude, increasing the mining pipe large diameter stepped section length and damping will decrease the longitudinal and transverse vibration simultaneously. When the towing velocity is between $0-2.8 \mathrm{~m} / \mathrm{s}$, the longitudinal vibration intensity is large, which is the main vibration mode. When the towing velocity is $2.8 \mathrm{~m} / \mathrm{s}$, the critical point is reached, and the longitudinal and transverse vibrations have the same intensity. When the towing velocity is greater than $2.8 \mathrm{~m} / \mathrm{s}$, the transverse vibration intensity is gradually greater than the longitudinal vibration intensity; at this time, the control of the transverse vibration should be appropriately increased.
\end{abstract}

\section{Introduction}

With the development of the society and the rapid increase of world population, the demand for mineral resources in various industries is also increasing day by day [1]. Due to the remarkable improvement of science and technology, the resources on the land have been continuously discovered and exploited; after a long time of unrestrained predatory excavation, the land resources began to be gradually exhausted [2]. The seabed contains rich mineral resources such as polymetallic nodules, cobalt-rich crusts, and sulfides. Taking the ocean as the turning point for resource development can alleviate the resource crisis in countries around the world [3]. The deep sea mining system is a multilink system engineering, which can collect the mineral resources from the seabed and transport them back to the land; it often faces the harsh and complex working environment in the ocean [4]. The mining pipe subsystem is an important part of the deep sea mining system, which produces a series of vibration deformation under the action of ocean currents and waves [5]. When the vibration is too large, it will cause the pipe to break, which will cause great economic loss and safety accident; therefore, the vibration amplitude of the mining pipe should be reduced as far as possible [6]. In order to ensure the safety and stability of the deep sea mining system, it is necessary to study the vibration characteristics of the mining pipe.

Numerous studies have been conducted on the dynamic response of transport pipes used for deep sea mining. American research scholars Cheng and Chung have studied the pipe nonlinear transient characteristics, and the axial stress was analyzed in detail [7]. Chung and Cheng optimized the pipe structure and added the vibration damping device, the lower-end boundary conditions are set as free end 
and fixed end, and the study shows that the dynamic response of the mining pipe caused by external excitation is weakened after the addition of the vibration damping device [8]. Achouyab and Bahrar used the FEM to analyze the pipe displacement offset under the fluid-solid coupling action [9]. The Korean scholar Hong et al. used the concentrated mass method to analyze the three-dimensional dynamics of the deep sea mining pipe and obtained the mining pipe towing motion law [10]. Haluk used the separation variable method to analyze the pipe longitudinal vibration and obtained the variation law of the longitudinal vibration under different damping [11]. Mannini et al. researched the aeroelastic behavior of a rectangular cylinder with a side ratio of 1.5 in the turbulent flow, the corresponding oscillation response of the model is obtained through experiments, and the response of the cylinder is found to be little sensitive to flow velocity fluctuations with small intensity, but is remarkably affected by strong turbulence $[12,13]$.

Professor Wu et al. of China used FEM to analyze the stability of the deep sea mining lifting system. He mainly studied the influence of mining ship heave motion on the axial tension of the mining pipe and obtained the law of axial stress changing with time [14]. Professor Li et al. analyzed the dynamic characteristics of $1000 \mathrm{~m}$ deep sea mining pipe, obtained the influence of inner flow and ore bin weight on the displacement of the mining pipe under different working conditions, and obtained the stress distribution law [15]. Professor Xu et al. studied the effect of lateral swing on the transportation characteristics of deep sea mining pipes [16]. Dr. Qiu carried out mechanical analysis on $1000 \mathrm{~m}$ mining pipe, deduced the longitudinal vibration equation with Galerkin theory, and obtained the law of longitudinal vibration and axial force changing with wave frequency [17].

In summary, the above scholars have done a lot of work on deep sea mining systems, but most of the research focuses on the analysis of the dynamic characteristics and offset characteristics of the mining pipe when the mining ship is stationary. There are few studies on the vibration characteristics of the $5000 \mathrm{~m}$ stepped mining pipe when the mining ship has towing velocity. In this paper, the FEM is used to analyze the mining pipe, and the vibration law under different towing velocities is obtained. The research methods and conclusions can provide reference for the system vibration control. In practical applications, the shock absorber can be installed reasonably according to the vibration conditions at different positions of the mining pipe, including the location and quantity of the shock absorber, and the shock absorber can also be adjusted in real time, such as adjusting the stiffness and damping appropriately to avoid the resonance phenomenon, and the vibration absorber can also be added to the top of the pipe according to the vibration law to reduce the excitation amplitude from the source, and the type of vibration absorber can be determined according to the magnitude of the vibration amplitude.

\section{Modeling}

A concept model can be seen in Figure 1. The deep sea mining system includes mining ship, flexible pipe, mining

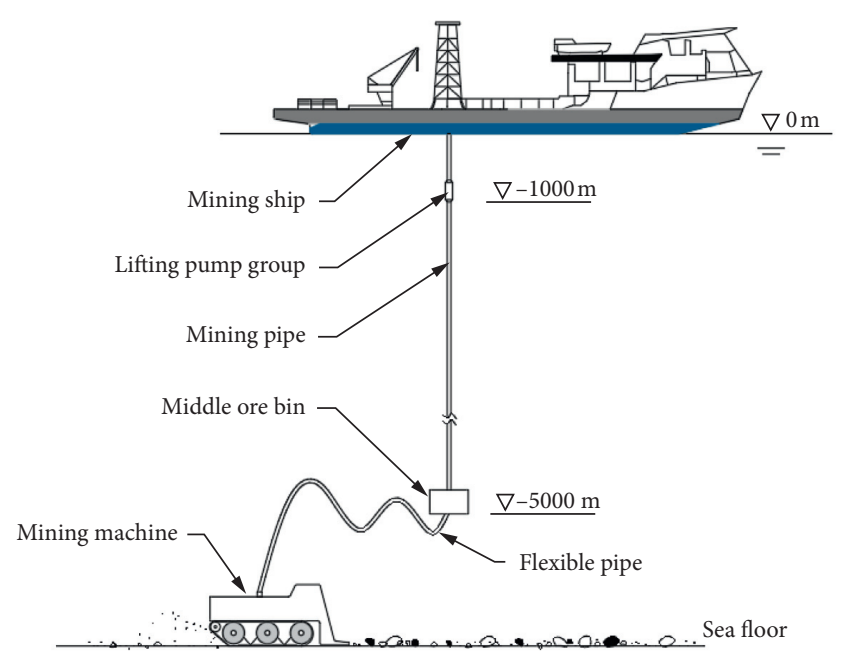

Figure 1: Sketch of the deep sea mining system.

machine, and mining pipe subsystem [18]. The mining pipe subsystem is composed of mining pipe, middle ore bin, pump, and shock absorber [19]. The flexible pipe can transport minerals collected by the mining machine to the ore bin and can also play the buffering role [20]. The mining machine is used to collect the mineral resources, the pump provides power, and the mining pipe and flexible pipe are used to transport minerals to the mining ship; then, use the transport subship to transport the mineral resources back to land to complete the work of mineral mining [21].

Figure 2 is the sketch of the mining pipe subsystem. As the main component of the subsystem, the mining pipe is thousands of meters long. It is not only used for the transportation of minerals but also the installation carrier for cables and power components [22]. The pipe top moves with the ship in heave motion $(u(t))$ [23]. Using the stepped pipe can reduce the load pressure on the pipe, the pipe is divided into four steps, and the diameter of the pipe gradually decreases from the top to the bottom [24]. Ignore the flexible pipe impact and treat the bottom end as a free end [25].

\section{Theoretical Analysis}

The FEM is a numerical method for solving mathematical and physical problems based on the variational principle. It can be applied to the calculation of complex problems such as dynamic analysis, nonlinear analysis, and multiphysics coupling analysis. The basic idea of the FEM can be summed up in two aspects: discretization and difference. The discretization is to divide the continuum into the combination of finite elements, and the difference is to select an interpolation function for each element to approximately solve the unknown function of the whole region. In this way, the equation of the continuum can be solved and calculated.

\subsection{Theoretical Analysis of the Longitudinal Vibration}

3.1.1. Element Matrix Analysis. In the longitudinal and transverse vibration analysis of the mining pipe, the mining 


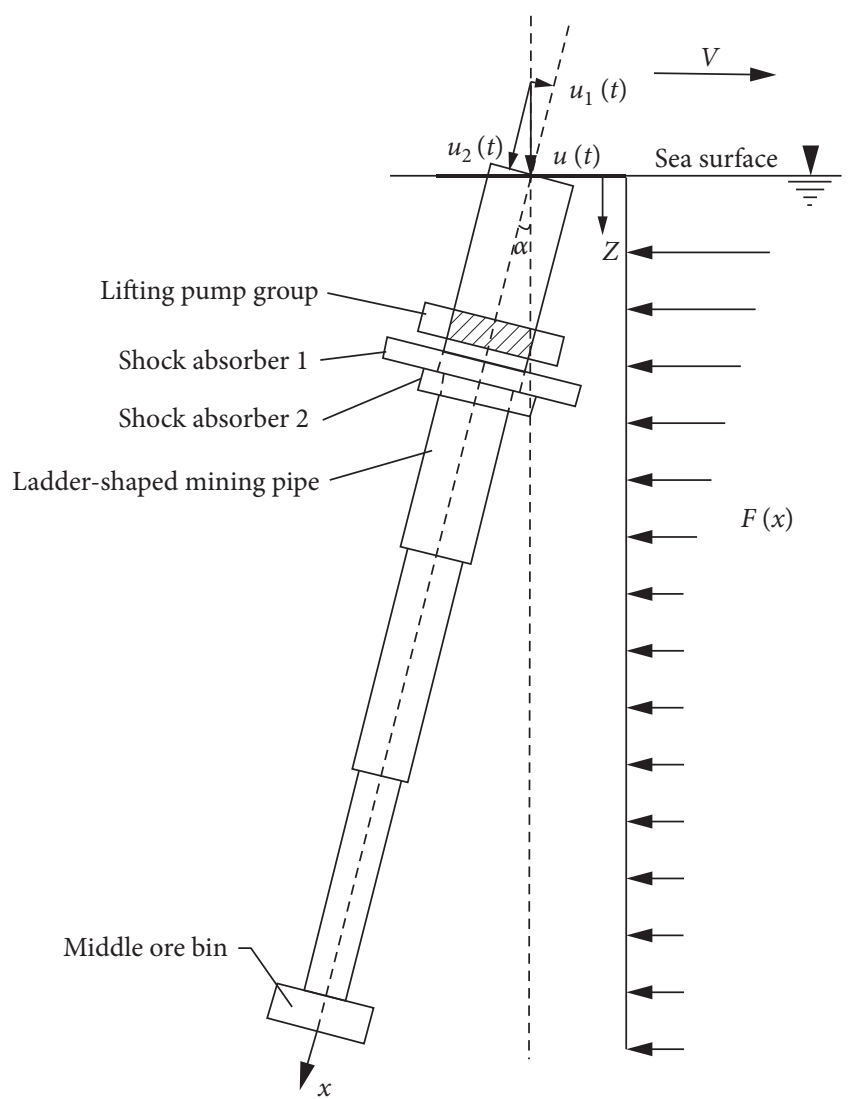

Figure 2: Mining pipe subsystem sketch.

pipe is simplified as the two-dimensional beam-bar element, and any small element is selected; as shown in Figure 3, $i$ and $j$ are the nodes at both ends, $u$ and $v$ are the linear displacement components, and the element node displacement vector is expressed as follows:

$$
[\xi]=\left[\begin{array}{llll}
u_{i} & v_{i} & u_{j} & v_{j}
\end{array}\right]^{T}
$$

Using the Hermite difference to get the interpolation function [26]:

$$
\begin{aligned}
& N_{1}=1-\frac{x}{l} \\
& N_{2}=\frac{x}{l} \\
& N_{3}=1-\frac{3 x^{2}}{l^{2}}+\frac{2 x^{3}}{l^{3}}, \\
& N_{4}=\frac{3 x^{2}}{l^{2}}-\frac{2 x^{3}}{l^{3}} .
\end{aligned}
$$

In equations (2)-(5), $l$ is the element length and $N_{1}, N_{2}$, $N_{3}$, and $N_{4}$ are the interpolation function of the beam-bar element. follows:

The element node displacement can be expressed as

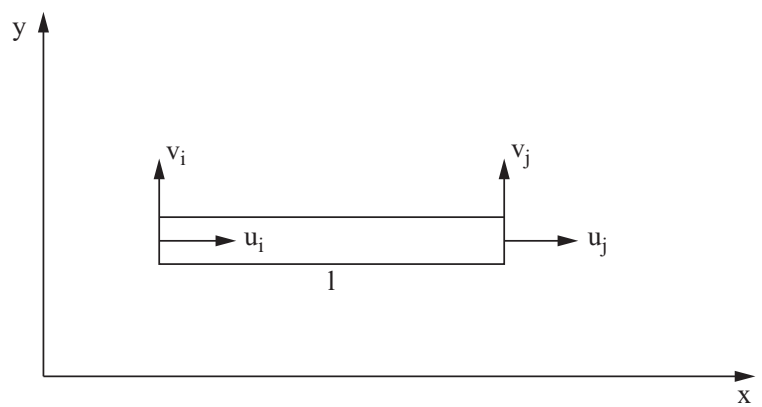

Figure 3: The diagram of element node displacement.

$$
\begin{aligned}
u & =\left[\begin{array}{cccc}
N_{1} & 0 & N_{2} & 0 \\
0 & N_{3} & 0 & N_{4}
\end{array}\right] \cdot\left[\begin{array}{llll}
u_{i} & v_{i} & u_{j} & v_{j}
\end{array}\right]^{T}, \\
{[N] } & =\left[\begin{array}{cccc}
N_{1} & 0 & N_{2} & 0 \\
0 & N_{3} & 0 & N_{4}
\end{array}\right] .
\end{aligned}
$$

The geometric equation can be written as follows:

$$
\varepsilon_{x}=\frac{\mathrm{d} u}{\mathrm{~d} x} .
$$

The geometric matrix $[B]$ is represented as follows:

$$
[B]=\left[\begin{array}{cccc}
N_{1}^{\prime} & 0 & N_{2}^{\prime} & 0 \\
0 & N_{3}^{\prime} & 0 & N_{4}^{\prime}
\end{array}\right] .
$$

The element stress can be expressed as follows:

$$
\begin{aligned}
\sigma & =\varepsilon E, \\
{[H] } & =E .
\end{aligned}
$$

The calculation formula of the element stiffness matrix is as follows:

$$
\left[K^{e}\right]=\iiint_{v}[B]^{T}[H][B] \mathrm{d} v .
$$

The calculation formula of the element mass matrix is as follows:

$$
\left[M^{e}\right]=\iiint_{v} m_{h}[N]^{T}[N] \mathrm{d} v
$$

where $m_{h}$ is the mining pipe density.

Through formulas (10) and (11), the element stiffness and mass matrix can be obtained, and the formula is expressed as follows:

$$
\begin{aligned}
& {\left[K^{e}\right]=\left[\begin{array}{llll}
k_{11} & k_{12} & k_{13} & k_{14} \\
k_{21} & k_{22} & k_{23} & k_{24} \\
k_{31} & k_{32} & k_{33} & k_{34} \\
k_{41} & k_{42} & k_{43} & k_{44}
\end{array}\right],} \\
& {\left[M^{e}\right]=\left[\begin{array}{llll}
m_{11} & m_{12} & m_{13} & m_{14} \\
m_{21} & m_{22} & m_{23} & m_{24} \\
m_{31} & m_{32} & m_{33} & m_{34} \\
m_{41} & m_{42} & m_{43} & m_{44}
\end{array}\right] .}
\end{aligned}
$$


In equations (12) and (13),

$$
\begin{aligned}
& k_{11}=k_{33}=\frac{E A_{h}}{l}, \\
& k_{12}=k_{21}=0 \text {, } \\
& k_{13}=k_{31}=-\frac{E A_{h}}{l}, \\
& k_{14}=k_{41}=0 \text {, } \\
& k_{22}=k_{44}=\frac{6 E A_{h}}{5 l}, \\
& k_{23}=k_{32}=0 \text {, } \\
& k_{24}=k_{42}=-\frac{6 E A_{h}}{5 l}, \\
& k_{34}=k_{43}=0 \text {, } \\
& m_{11}=m_{33}=\frac{l}{3} m_{h}, \\
& m_{12}=m_{21}=0 \text {, } \\
& m_{13}=m_{31}=\frac{l}{6} m_{h}, \\
& m_{14}=m_{41}=0 \text {, } \\
& m_{22}=m_{44}=\frac{13 l}{35} m_{h} \text {, } \\
& m_{23}=m_{32}=0 \text {, } \\
& m_{24}=m_{42}=-\frac{13 l}{35} m_{h} \\
& m_{34}=m_{43}=0 \text {, }
\end{aligned}
$$

where $A_{h}$ is the cross-sectional area.

3.1.2. Overall Matrix Analysis. The element matrix is assembled into the overall matrix. As shown in Figure 4, the $5000 \mathrm{~m}$ mining pipe is divided into 200 units, 201 nodes, and 402 degrees of freedom.

The $n$th element stiffness matrix is $K^{e(n)}$, $n=1,2, \ldots, 200$. The subelements are $k_{r s}^{(n)}, r$, and $s$ ranging from $1-2$. $k_{22}^{n}$ in the $n$th matrix is added to $k_{11}^{(n+1)}$ in the $(n+1)$ th matrix; this point is taken as the basic point, and remaining items are added in turn to obtain the overall stiffness matrix, which is expressed as follows [27]:

$$
K=\left[\begin{array}{ccccc}
k_{11} & k_{12} & \cdots & k_{1,401} & k_{1,402} \\
\vdots & & & & \vdots \\
\vdots & & k_{p q} & & \vdots \\
k_{402,1} & k_{402,2} & \cdots & k_{402,401} & k_{402,402}
\end{array}\right] .
$$

Similarly, the overall mass matrix can be obtained, which is expressed as follows:

$$
M=\left[\begin{array}{ccccc}
m_{11} & m_{12} & \cdots & m_{1,401} & m_{1,402} \\
\vdots & & & & \vdots \\
\vdots & & m_{p q} & & \vdots \\
m_{402,1} & m_{402,2} & \cdots & m_{402,401} & m_{402,402}
\end{array}\right] .
$$

\subsection{Theoretical Analysis of the Transverse Vibration}

3.2.1. Element Matrix Analysis. In the transverse vibration of the mining pipe, take any section of the beam-bar element, as shown in Figure 5. $\theta$ represents the offset angle; then, the displacement vector of the element node is expressed as follows:

$$
[\xi]=\left[\begin{array}{llllll}
u_{i} & v_{i} & \theta_{i} & u_{j} & v_{j} & \theta_{j}
\end{array}\right]^{T} .
$$

Using the Hermite difference to get the interpolation function:

$$
\begin{aligned}
& N_{5}=1-\frac{x}{l}, \\
& N_{6}=\frac{x}{l}, \\
& N_{7}=1-\frac{3 x^{2}}{l^{2}}+\frac{2 x^{3}}{l^{3}}, \\
& N_{8}=x-\frac{2 x^{2}}{l}+\frac{x^{3}}{l^{2}}, \\
& N_{9}=\frac{3 x^{2}}{l^{2}}-\frac{2 x^{3}}{l^{3}}, \\
& N_{10}=-\frac{x^{2}}{l^{2}}+\frac{x^{3}}{l^{3}} .
\end{aligned}
$$

The element node displacement function is expressed as follows:

$$
\begin{aligned}
u & =\left[\begin{array}{cccccc}
N_{5} & 0 & 0 & N_{6} & 0 & 0 \\
0 & N_{7} & N_{8} & 0 & N_{9} & N_{10}
\end{array}\right] \cdot\left[\begin{array}{llllll}
u_{i} & v_{i} & \theta_{i} & u_{j} & v_{j} & \theta_{j}
\end{array}\right]^{T}, \\
{\left[N^{*}\right] } & =\left[\begin{array}{cccccc}
N_{5} & 0 & 0 & N_{6} & 0 & 0 \\
0 & N_{7} & N_{8} & 0 & N_{9} & N_{10}
\end{array}\right] .
\end{aligned}
$$

The geometric equation formula is as follows:

$$
\begin{aligned}
& \varepsilon_{x}=\frac{\mathrm{d} u}{\mathrm{~d} x}, \\
& \gamma_{x}=-\frac{\mathrm{d}^{2} v}{\mathrm{~d} x^{2}},
\end{aligned}
$$

where $\varepsilon_{x}$ is the axial strain of the element and $\gamma_{x}$ is the curvature.

The geometric matrix $\left[B^{*}\right]$ is expressed as follows: 


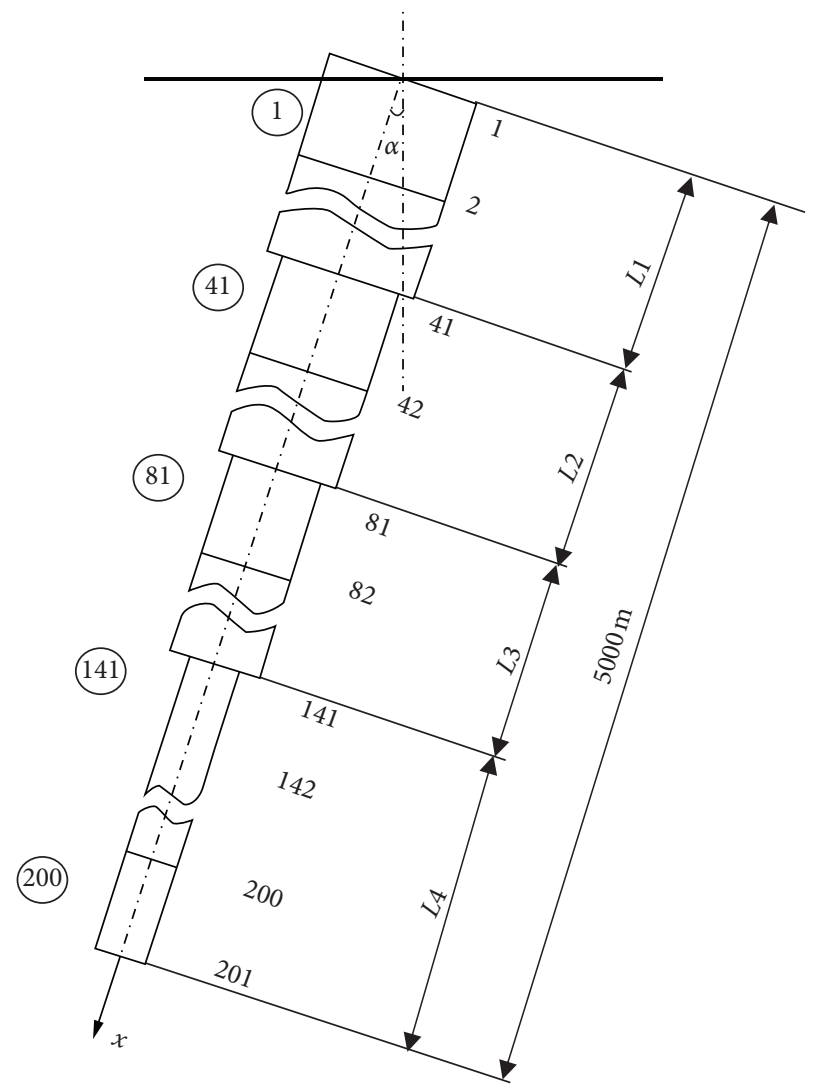

Figure 4: Discrete schematic diagram of the mining pipe.

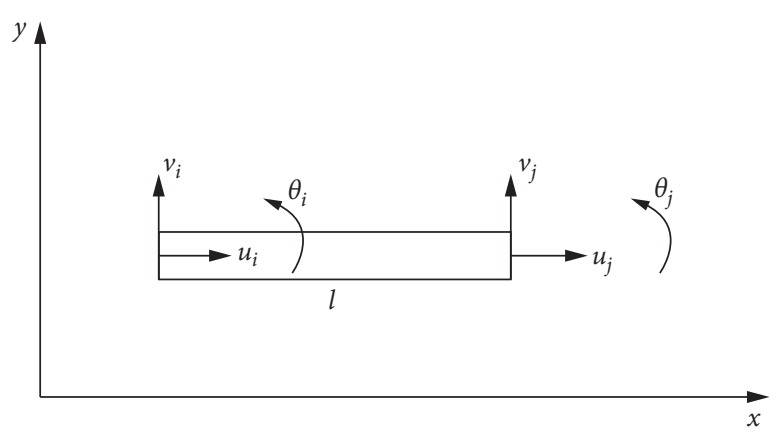

Figure 5: The diagram of element node displacement.

$$
\left[B^{*}\right]=\left[\begin{array}{cccccc}
N_{5}^{\prime} & 0 & 0 & N_{6}^{\prime} & 0 & 0 \\
0 & N_{7}^{\prime \prime} & N_{8}^{\prime \prime} & 0 & N_{9}^{\prime \prime} & N_{10}^{\prime \prime}
\end{array}\right] .
$$

The element stress is expressed as follows:

$$
\begin{aligned}
\sigma^{*} & =\left[H^{*}\right]\left[\begin{array}{ll}
\varepsilon_{x} & \gamma_{x}
\end{array}\right]^{T}, \\
{\left[H^{*}\right] } & =\left[\begin{array}{cc}
E A_{h} & 0 \\
0 & E I
\end{array}\right],
\end{aligned}
$$

where $I$ is the inertia moment.

The calculation formula of the element stiffness matrix is as follows:

$$
\left[K^{e^{*}}\right]=\iiint_{v}\left[B^{*}\right]^{T}\left[H^{*}\right]\left[B^{*}\right] \mathrm{d} v .
$$

The calculation formula of the element mass matrix is as follows:

$$
\left[M^{e *}\right]=\iiint_{v} m_{h}\left[N^{*}\right]^{T}\left[N^{*}\right] \mathrm{d} v .
$$

Then, the element stiffness and mass matrix are expressed as follows:

$$
\left[K^{e *}\right]=\left[\begin{array}{llllll}
k_{11} & k_{12} & k_{13} & k_{14} & k_{15} & k_{16} \\
k_{21} & k_{22} & k_{23} & k_{24} & k_{25} & k_{26} \\
k_{31} & k_{32} & k_{33} & k_{34} & k_{35} & k_{36} \\
k_{41} & k_{42} & k_{43} & k_{44} & k_{45} & k_{46} \\
k_{51} & k_{52} & k_{53} & k_{54} & k_{55} & k_{56} \\
k_{61} & k_{62} & k_{63} & k_{64} & k_{65} & k_{66}
\end{array}\right],
$$

$$
\left[M^{e *}\right]=\left[\begin{array}{llllll}
m_{11} & m_{12} & m_{13} & m_{14} & m_{15} & m_{16} \\
m_{21} & m_{22} & m_{23} & m_{24} & m_{25} & m_{26} \\
m_{31} & m_{32} & m_{33} & m_{34} & m_{35} & m_{36} \\
m_{41} & m_{42} & m_{43} & m_{44} & m_{45} & m_{46} \\
m_{51} & m_{52} & m_{53} & m_{54} & m_{55} & m_{56} \\
m_{61} & m_{62} & m_{63} & m_{64} & m_{65} & m_{66}
\end{array}\right] .
$$

In equations (25) and (26), 


$$
\begin{aligned}
& k_{11}=k_{44}=\frac{E A_{h}}{l}, \\
& k_{12}=k_{21}=0 \text {, } \\
& k_{13}=k_{31}=0 \text {, } \\
& k_{14}=k_{41}=-\frac{E A_{h}}{l}, \\
& k_{15}=k_{51}=0 \text {, } \\
& k_{16}=k_{61}=0 \text {, } \\
& k_{22}=k_{55}=\frac{12 E I}{l^{3}}, \\
& k_{23}=k_{32}=\frac{6 E I}{l^{2}}, \\
& k_{24}=k_{42}=0 \text {, } \\
& k_{25}=k_{52}=-\frac{12 E I}{l^{3}}, \\
& k_{26}=k_{62}=\frac{6 E I}{l^{2}}, \\
& k_{33}=k_{66}=\frac{4 E I}{l}, \\
& k_{34}=k_{43}=0 \text {, } \\
& k_{35}=k_{53}=-\frac{6 E I}{l^{2}}, \\
& k_{36}=k_{63}=\frac{2 E I}{l}, \\
& k_{45}=k_{54}=0 \text {, } \\
& k_{46}=k_{64}=0 \text {, } \\
& k_{56}=k_{65}=-\frac{6 E I}{l^{2}}, \\
& m_{11}=m_{44}=\frac{l}{3} m_{h}, \\
& m_{12}=m_{21}=0, \\
& m_{13}=m_{31}=0 \text {, } \\
& m_{14}=m_{41}=\frac{l}{6} m_{h}, \\
& m_{15}=m_{51}=0, \\
& m_{16}=m_{61}=0 \text {, } \\
& m_{22}=m_{55}=\frac{13 l}{35} m_{h}, \\
& m_{23}=m_{32}=\frac{11 l^{2}}{210} m_{h}, \\
& m_{24}=m_{42}=0, \\
& m_{25}=m_{52}=\frac{9 l}{70} m_{h}, \\
& m_{26}=m_{62}=-\frac{13 l^{2}}{420} m_{h}, \\
& m_{33}=m_{66}=\frac{l^{3}}{105} m_{h}, \\
& m_{34}=m_{43}=0, \\
& m_{35}=m_{53}=\frac{13 l^{2}}{420} m_{h}, \\
& m_{36}=m_{63}=-\frac{l^{3}}{140} m_{h}, \\
& m_{45}=m_{54}=0, \\
& m_{46}=m_{64}=0 \text {, } \\
& m_{56}=m_{65}=-\frac{11 l^{2}}{210} m_{h} \text {. }
\end{aligned}
$$

3.2.2. Overall Matrix Analysis. Similarly, the $5000 \mathrm{~m}$ mining pipe is divided into 200 units; each unit is $25 \mathrm{~m}$ long and has the total of 201 nodes. Each node contains 3 degrees of freedom, so there are 603 degrees of freedom in total.

The $n$th element stiffness matrix is $K^{e *(n)}$, $n=1,2, \ldots, 200$. The subelements are $k_{r^{*} s^{*}}^{*(n)}, r^{*}$, and $s^{*}$ ranging from $1-6 . k_{44}^{* n}$ in the $n$th matrix is added to $k_{11}^{*(n+1)}$ in the $(n+1)$ th matrix. Based on this point, the remaining items are added in turn to obtain the overall stiffness matrix, which is expressed as follows:

$$
K^{*}=\left[\begin{array}{ccccc}
k_{11} & k_{12} & \cdots & k_{1,602} & k_{1,603} \\
\vdots & & & & \vdots \\
\vdots & & k_{p q} & & \vdots \\
k_{603,1} & k_{603,2} & \cdots & k_{603,602} & k_{603,603}
\end{array}\right] .
$$

Similarly, the overall mass matrix can be obtained, which is expressed as follows:

$$
M^{*}=\left[\begin{array}{ccccc}
m_{11} & m_{12} & \cdots & m_{1,602} & m_{1,603} \\
\vdots & & & & \vdots \\
\vdots & & m_{p q} & & \vdots \\
m_{603,1} & m_{603,2} & \cdots & m_{603,602} & m_{603,603}
\end{array}\right] .
$$

3.3. Load Analysis. The working environment of the mining pipe is complex, which is affected by the hydrodynamic force, pipeline gravity, and seawater buoyancy in the ocean [28]. In the actual sea conditions, under the action of ocean current, the mining pipe will be slightly offset, and under the action of mining ship excitation, the mining pipe will have vibration response [29]. According to the Morison equation, the ocean hydrodynamic force is composed of velocity force and inertial force. The calculation formula is as follows:

$$
F=F_{D}+F_{M},
$$

where $F_{D}$ is the velocity force vector and $F_{M}$ is the inertial force vector:

$$
F_{D}=F_{n}+F_{t},
$$

where $F_{n}$ is the normal velocity force and $F_{t}$ is the tangential velocity force. The calculation formula is as follows:

$$
\begin{aligned}
& F_{n}=\frac{1}{2} C_{D} D \rho_{w} v_{s v}^{2} \cos ^{2} \alpha, \\
& F_{t}=\frac{\pi}{2} C_{t} D \rho_{w} v_{s v}^{2} \sin ^{2} \alpha .
\end{aligned}
$$

The calculation formula of the inertial force is as follows:

$$
\begin{aligned}
F_{M} & =\frac{\pi}{4} C_{M} D^{2} \rho_{w} v_{s v}^{\prime} \cos \alpha, \\
v_{s v} & =v_{w v}+v_{c}+v_{p}, \\
v_{c} & =0.15+1.6 \times\left(\frac{5000+z}{5000}\right)^{12},
\end{aligned}
$$




$$
\left|v_{w v}\right|_{\max }=\left|\frac{\pi H_{w}}{T} e^{4 \pi^{2} z / T^{2} g}\right| .
$$

In equations (33)-(36), $C_{D}$ is the normal resistance coefficient, the value is 1.2 [30], $C_{t}$ is the tangential resistance coefficient, the value range is $0.01-0.04$ [31], $C_{M}$ is the inertial resistance coefficient, the value is 2.0 [32], $D$ is the outside diameter of the pipe, $\rho_{w}$ is sea water density, $v_{s v}$ is the relative velocity vector between sea water and pipe, $v_{w v}$ is the fluid velocity under the waves' influence, $v_{c}$ is the fluid velocity under the ocean influence, $v_{p}$ is the velocity vector of the pipe motion, $z$ is the water depth, $H_{w}$ is the wave height, and $T$ is the wave period.

Taking the moment to the top of the pipe, the calculation formula of the pipe offset angle is as follows [33]:

$$
\int_{0}^{L} F x \mathrm{~d} x-\int_{0}^{L} m_{h} g x \sin \alpha \mathrm{d} x-m g L \sin \alpha=0,
$$

where $m$ is the middle ore bin weight and $L$ is the pipe length.

Then, the external force matrix is as follows:

$$
F(t)=\left[\begin{array}{llllllll}
F\left(t_{1}\right) & 0 & 0 & \cdots & \cdots & 0 & 0 & 0
\end{array}\right]^{T} .
$$

The longitudinal forces can be expressed as follows:

$$
F(t)=\left[\begin{array}{lllllllll}
F_{D} \cos \alpha \sin \omega t & 0 & 0 & \cdots & \cdots & 0 & 0 & 0
\end{array}\right]^{T} .
$$

The transverse forces can be expressed as follows:

$$
\begin{aligned}
F(t) & =\left[\begin{array}{lllllllll}
F_{D} \sin \alpha \sin \omega t & 0 & 0 & \cdots & \cdots & 0 & 0 & 0
\end{array}\right]^{T}, \\
F_{D} & =M \omega^{2} z_{s a},
\end{aligned}
$$

where $z_{s a}$ is the mining ship heave amplitude, which can be calculated by Moore's empirical formula [34], and $M$ is the displacement of the mining ship.

3.4. Vibration Equation. The vibration equation is as follows [35]:

$$
M \zeta^{\prime \prime}+C \zeta^{\prime}+K \zeta=F(t)
$$

where $C$ is the damping matrix, which can be expressed as the viscous damping coefficient $c$ multiplied by the matrix [36].

The initial states are as follows:

$$
\begin{aligned}
& \zeta_{1}(x, 0)=u_{1}, \\
& \zeta_{2}(x, 0)=u_{2} .
\end{aligned}
$$

The Wilson- $\theta$ direct integral method is calculated as follows [37]:

$$
\begin{aligned}
& \zeta(t+\Delta t)=\zeta_{t}+\zeta_{t}^{\prime} \Delta t+\frac{\Delta t^{2}}{6}\left(\zeta_{t+\Delta t}^{\prime \prime}+2 \zeta_{t}^{\prime \prime}\right), \\
& \zeta_{\prime}(t+\Delta t)=\zeta_{t}^{\prime}+\frac{\Delta t}{2}\left(\zeta_{t+\Delta t}^{\prime \prime}+\zeta_{t}^{\prime \prime}\right),
\end{aligned}
$$

$$
\zeta^{\prime \prime}(t+\Delta t)=\zeta_{t}^{\prime \prime}+\frac{1}{\theta}\left(\zeta_{t+\theta \Delta t}^{\prime \prime}-\zeta_{t}^{\prime \prime}\right)
$$

From time $t$ to $t+\Delta t$, the iterative solution should be performed according to formulas (43)-(45), until the set time is reached to complete the iterative calculation.

\section{Results and Discussion}

When the deep sea mining system is working, the mining ship can mine while sailing [38]. At the beginning, the velocity of the mining ship accelerates from $0 \mathrm{~m} / \mathrm{s}$ to the maximum constant towing velocity, and at the end, the mining ship decelerates from the maximum running velocity to $0 \mathrm{~m} / \mathrm{s}$. In this process, the vibration response of the mining pipe is directly related to the towing velocity of the mining ship [39]. As shown in Figure 6, $w$ represents the towing function, $0-t_{1}$ is the constant accelerated towing stage, $t_{1}-t_{2}$ is the constant velocity towing stage, $t_{2}-t_{3}$ is the constant decelerating towing stage, and $V$ is constant towing velocity; this paper mainly analyzes the constant velocity towing stage $\left(t_{1}-t_{2}\right)$.

The $5000 \mathrm{~m}$ mining pipe is divided into four steps. Table 1 is related parameters, the working environment is the level 6 working wind condition, and the mining pipe vibration law under different towing velocities is analyzed.

4.1. Natural Frequency Solution. The pipe top is connected to the mining ship. The bottom of the mining pipe is connected to the ore bin, and the effect of the flexible pipe on the mining pipe is not considered. The shock absorber provides controllable damping $c$. Since the length of the pipe is much larger than the thickness of the joint, the influence of flange weight can be ignored [40]. Then, the natural frequency calculation formula is as follows [41]:

$$
\operatorname{det}\left(K-f^{2} M\right)=0
$$

The first 20 order natural frequency values are shown in Tables 2 and 3.

4.2. Vibration Analysis of the Mining Pipe When the Towing Velocity is $0 \mathrm{~m} / \mathrm{s}$. When the mining ship towing velocity is $0 \mathrm{~m} / \mathrm{s}$, the ore bin weight is $30 \mathrm{t}$, and the damping is $200 \mathrm{~N} \cdot \mathrm{s} /$ $\mathrm{m}$, and the mining pipe vibration law is shown in Figures 7 and 8 .

As shown in Figures 7 and 8, the mining pipe longitudinal and transverse vibration response is irregular motion, and the oscillation phenomenon is obvious. When the towing velocity of the mining ship is $0 \mathrm{~m} / \mathrm{s}$, the longitudinal vibration amplitude is much larger than the transverse vibration amplitude. At this time, longitudinal vibration is the main vibration mode, and hysteresis response occurs in the mining pipe, and the hysteresis time increases gradually from the top to the bottom. As shown in Figures $7(\mathrm{a})-7(\mathrm{~d})$, the maximum longitudinal 


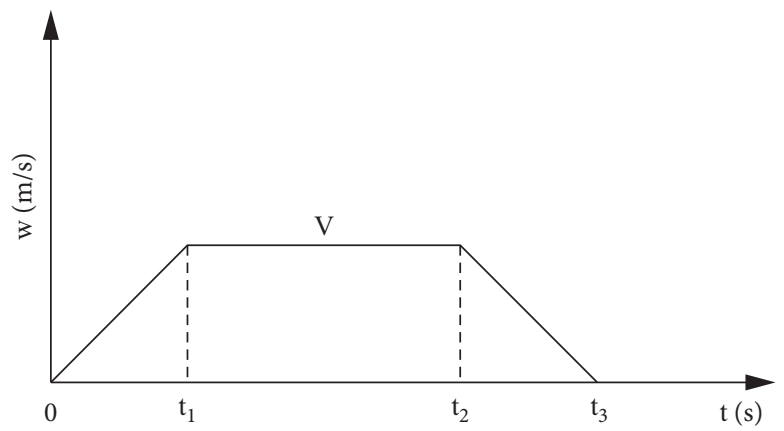

Figure 6: Towing process diagram.

TABLE 1: Related parameters of the mining pipe system.

\begin{tabular}{lcccc}
\hline Ladder section & 1 & 2 & 3 & 4 \\
\hline$L(\mathrm{~m})$ & 1000 & 1000 & 1500 & 0.24 \\
$D_{2}(\mathrm{~m})$ & 0.28 & 0.26 & 0.20 & 1500 \\
$D_{1}(\mathrm{~m})$ & 0.20 & 0.20 & 108.46 & 0.22 \\
$m_{h}(\mathrm{~kg} / \mathrm{m})$ & 236.63 & 170.08 & 0.0139 & 0.20 \\
$A_{h}\left(\mathrm{~m}^{2}\right)$ & 0.0302 & 0.0217 & $8.430 \times 10^{-5}$ & 0.0066 \\
$I_{z}\left(\mathrm{~m}^{4}\right)$ & $2.230 \times 10^{-4}$ & $1.457 \times 10^{-4}$ & $1.686 \times 10^{-4}$ & $3.643 \times 10^{-5}$ \\
$J\left(\mathrm{~m}^{4}\right)$ & $4.460 \times 10^{-4}$ & $2.914 \times 10^{-4}$ & 210 & $2.286 \times 10^{-5}$ \\
$E(\mathrm{GPa})$ & 210 & 210 & 84 & 84 \\
$G(\mathrm{GPa})$ & 84 & 84 & & 210 \\
\hline
\end{tabular}

TABle 2: Longitudinal natural frequency.

\begin{tabular}{lc}
\hline Order number & Natural frequency $(\mathrm{Hz})$ \\
\hline 1 & 2.313 \\
2 & 5.057 \\
3 & 7.795 \\
4 & 11.83 \\
5 & 15.82 \\
6 & 19.74 \\
7 & 24.35 \\
8 & 26.05 \\
9 & 28.11 \\
10 & 31.59 \\
11 & 33.48 \\
12 & 35.58 \\
13 & 36.68 \\
14 & 38.69 \\
15 & 39.56 \\
16 & 40.78 \\
17 & 42.19 \\
19 & 45.81 \\
20 & 47.55 \\
\hline
\end{tabular}

vibration amplitude between $1000 \mathrm{~m}-5000 \mathrm{~m}$ decreases first and then increases from the top to the bottom, and the minimum value occurs at a certain position between $1000 \mathrm{~m}-3500 \mathrm{~m}$. As shown in Figures 8(a)-8(d), the maximum transverse vibration amplitude of the mining pipe between $1000 \mathrm{~m}-5000 \mathrm{~m}$ also decreases first and then increases, and the minimum amplitude occurs at a certain position between $2000 \mathrm{~m}-3500 \mathrm{~m}$.
TABLE 3: Transverse natural frequency.

\begin{tabular}{lc}
\hline Order number & Natural frequency $(\mathrm{Hz})$ \\
\hline 1 & 0.003536 \\
2 & 0.003603 \\
3 & 0.003883 \\
4 & 0.004142 \\
5 & 0.004501 \\
6 & 0.004674 \\
7 & 0.004782 \\
8 & 0.005007 \\
9 & 0.005141 \\
10 & 0.005820 \\
11 & 0.006449 \\
12 & 0.01190 \\
13 & 0.01334 \\
14 & 0.01566 \\
15 & 0.01711 \\
16 & 0.02094 \\
17 & 0.02317 \\
19 & 0.02627 \\
20 & 0.02751 \\
\hline
\end{tabular}

4.3. Vibration Analysis under Different Towing Velocities. When the towing velocity is $0 \mathrm{~m} / \mathrm{s}, 0.2 \mathrm{~m} / \mathrm{s}, 0.5 \mathrm{~m} / \mathrm{s}, 1.0 \mathrm{~m} / \mathrm{s}$, $2.0 \mathrm{~m} / \mathrm{s}$, and $3.0 \mathrm{~m} / \mathrm{s}$, respectively, the ore bin weight is $30 \mathrm{t}$ and the damping is $200 \mathrm{~N} \cdot \mathrm{s} / \mathrm{m}$; the pipe maximum vibration amplitude at different locations is shown in Figures 9 and 10.

In Figure 9, the maximum longitudinal vibration amplitude of the mining pipe from the top to the bottom decreases first and then increases, and at $1500 \mathrm{~m}$, the 


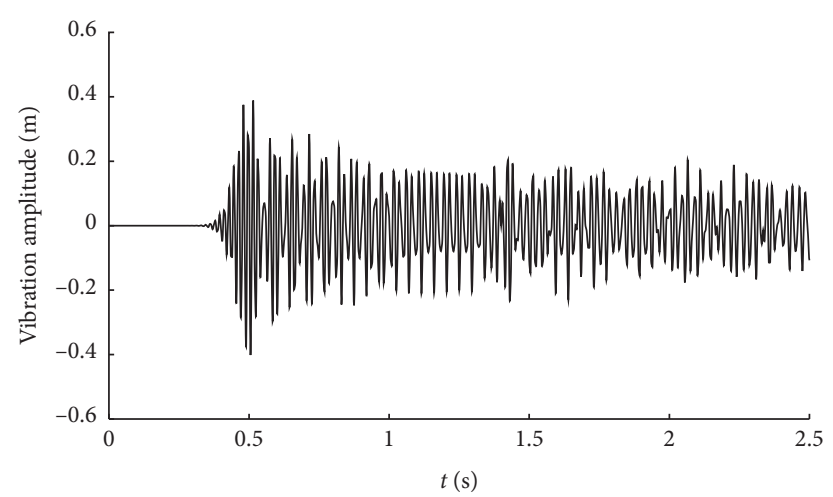

(a)

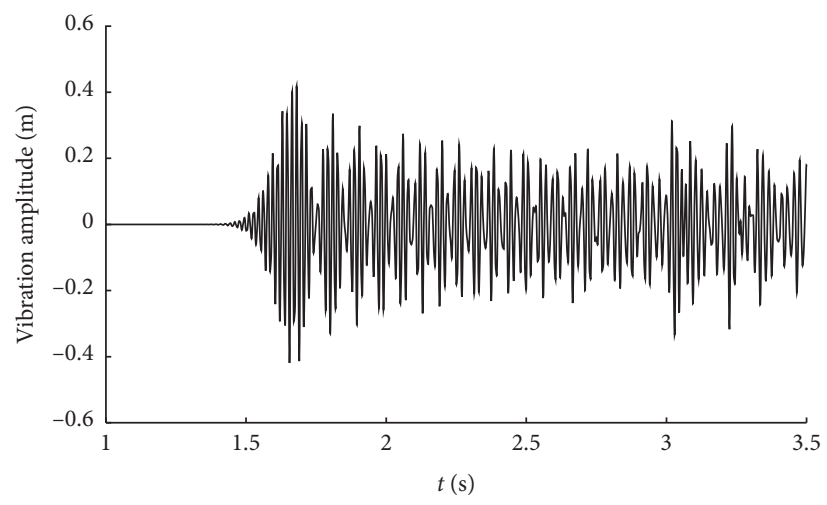

(c)

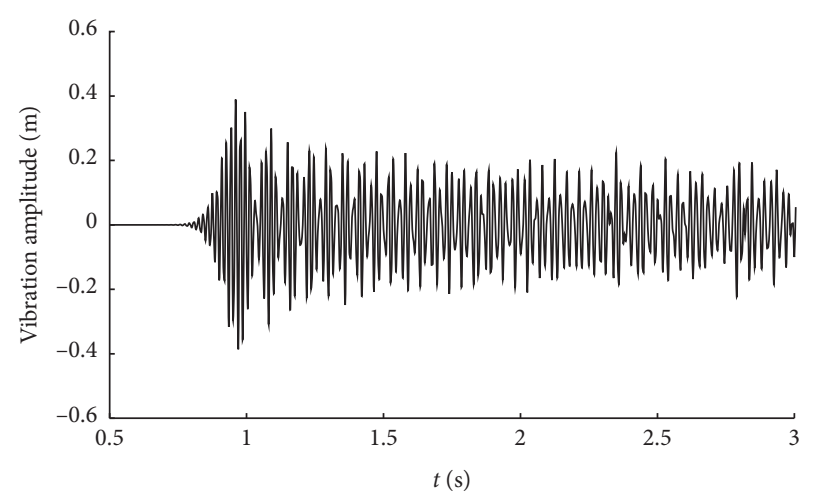

(b)

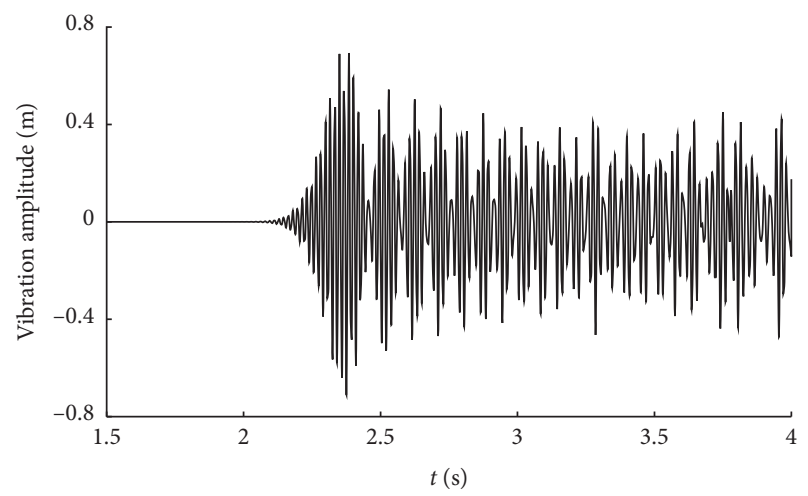

(d)

Figure 7: The mining pipe longitudinal vibration at different positions. (a) At $1000 \mathrm{~m}$. (b) At $2000 \mathrm{~m}$. (c) At $3500 \mathrm{~m}$. (d) At $5000 \mathrm{~m}$.

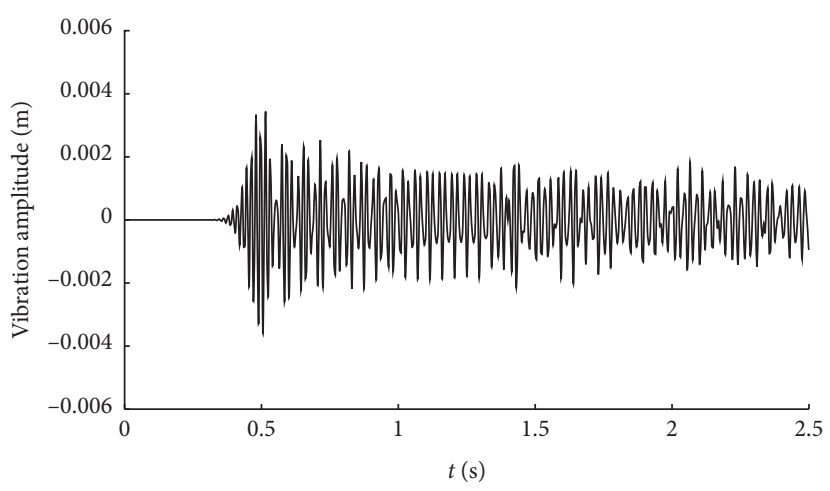

(a)

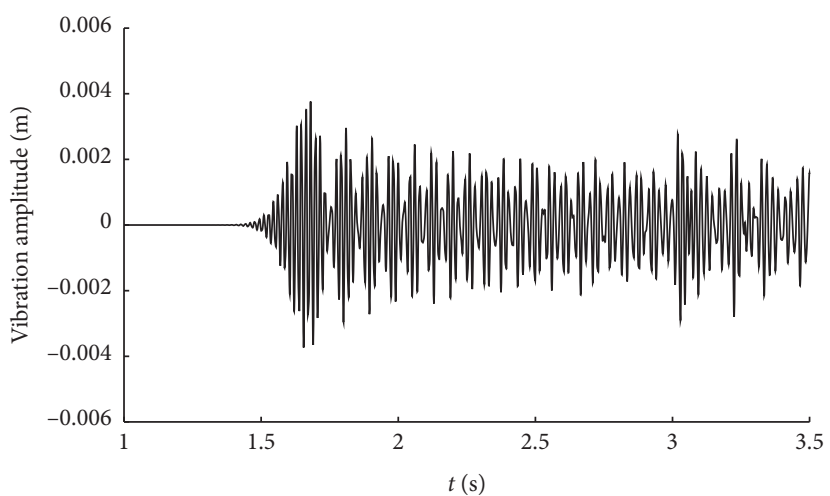

(c)

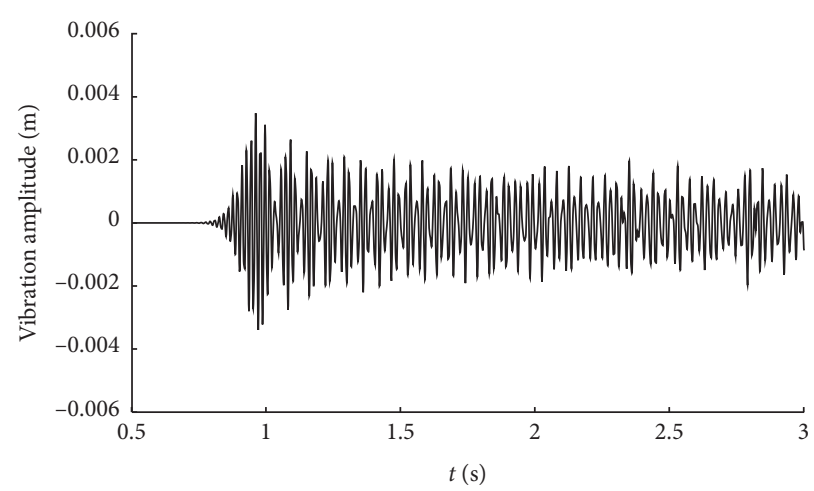

(b)

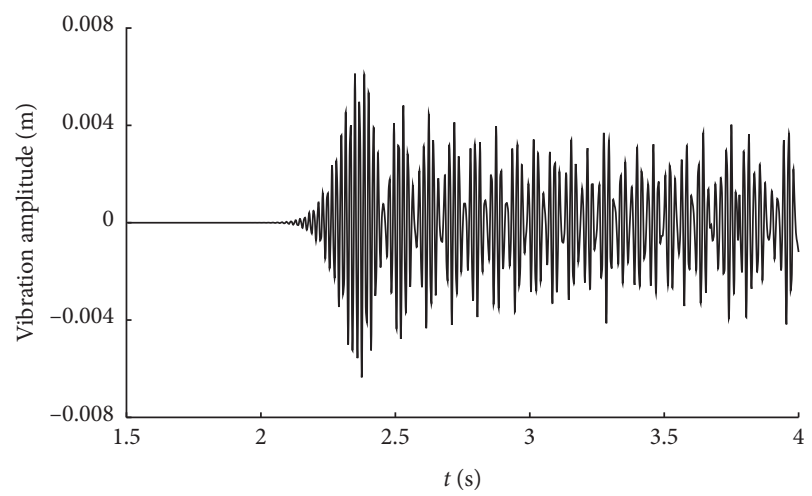

(d)

Figure 8: The mining pipe transverse vibration at different positions. (a) At $1000 \mathrm{~m}$. (b) At $2000 \mathrm{~m}$. (c) At $3500 \mathrm{~m}$. (d) At $5000 \mathrm{~m}$. 


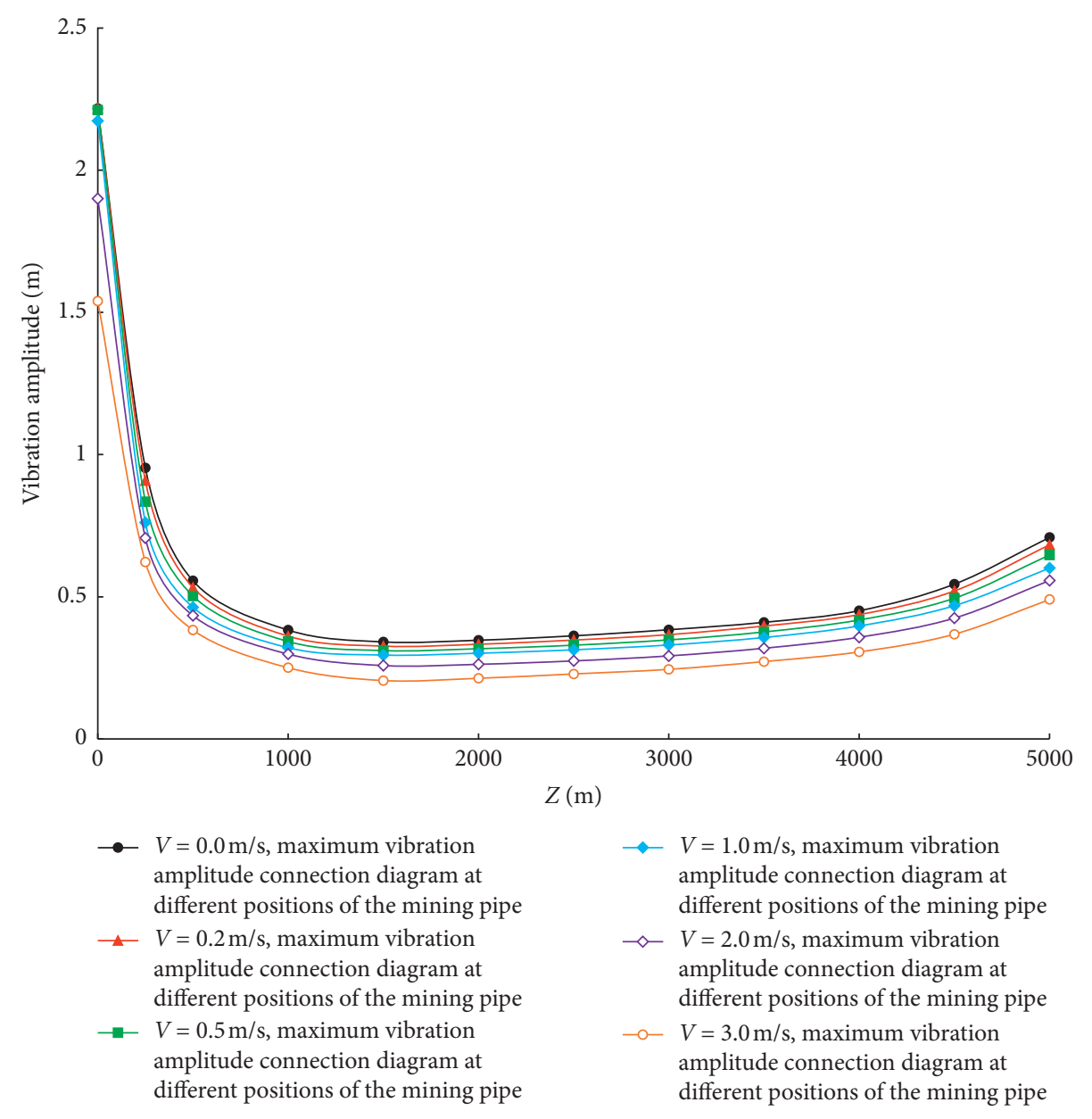

FIGURE 9: Variation diagram of maximum longitudinal vibration amplitude.

minimum vibration amplitude occurs; at the pipe top, the maximum vibration amplitude occurs. That is, the vibration amplitude gradually decreases at $0-1500 \mathrm{~m}$ and gradually increases at $1500 \mathrm{~m}-5000 \mathrm{~m}$. This is because the diameter of the mining pipe is large at $0-1500 \mathrm{~m}$, the contact area between nodes is large, and the energy consumption generated by the interaction force is large, so the vibration amplitude gradually decreases at this stage. At $1500 \mathrm{~m}-5000 \mathrm{~m}$, the pipe diameter decreases, the contact area between the nodes is reduced, energy consumption decreases, and the inertia force is increased, so the vibration amplitude gradually increases at $1500 \mathrm{~m}-5000 \mathrm{~m}$.

Similarly, in Figure 10, the pipe maximum transverse vibration amplitude decreases first and then increases from the top to the bottom, the minimum vibration amplitude appears at $3000 \mathrm{~m}$, and the maximum vibration value appears at the top of the pipe, and the vibration amplitude gradually decreases at $0-3000 \mathrm{~m}$ and increases at $3000 \mathrm{~m}-5000 \mathrm{~m}$. This is because the top of the pipe is directly excited by the mining ship, so the maximum value of vibration appears at the top, and then, there is the collision between the pipeline nodes, resulting in a loss of force, so the vibration amplitude gradually decreases. The diameter of the pipe at $0-3000 \mathrm{~m}$ is large, and the contact area is large, so the force loss is large, and the vibration amplitude decreases rapidly. The diameter of the pipeline at $0-3000 \mathrm{~m}$ is large, and the contact area is large, so the force loss is large, and the vibration amplitude decreases rapidly. At $3000 \mathrm{~m}-5000 \mathrm{~m}$, the inertial effect of the pipeline itself and the ore bin is enhanced, the pipeline contact area is reduced, and the force loss is reduced, so the vibration amplitude will show an upward trend again.

As shown in Figures 9 and 10, increasing the towing velocity can decrease the overall longitudinal vibration amplitude and increase the overall transverse vibration amplitude. This is because when the towing velocity increases, the mining pipe offset angle becomes larger, the transverse excitation increases, and the longitudinal excitation decreases, so the longitudinal vibration amplitude decreases and the transverse vibration amplitude increases. However, the change of the towing velocity will not change the vibration law of the mining pipe which first decreases and then increases, nor will it change the position where the minimum vibration value appears. When the towing velocity is less than $2.0 \mathrm{~m} / \mathrm{s}$, the longitudinal vibration amplitude is 


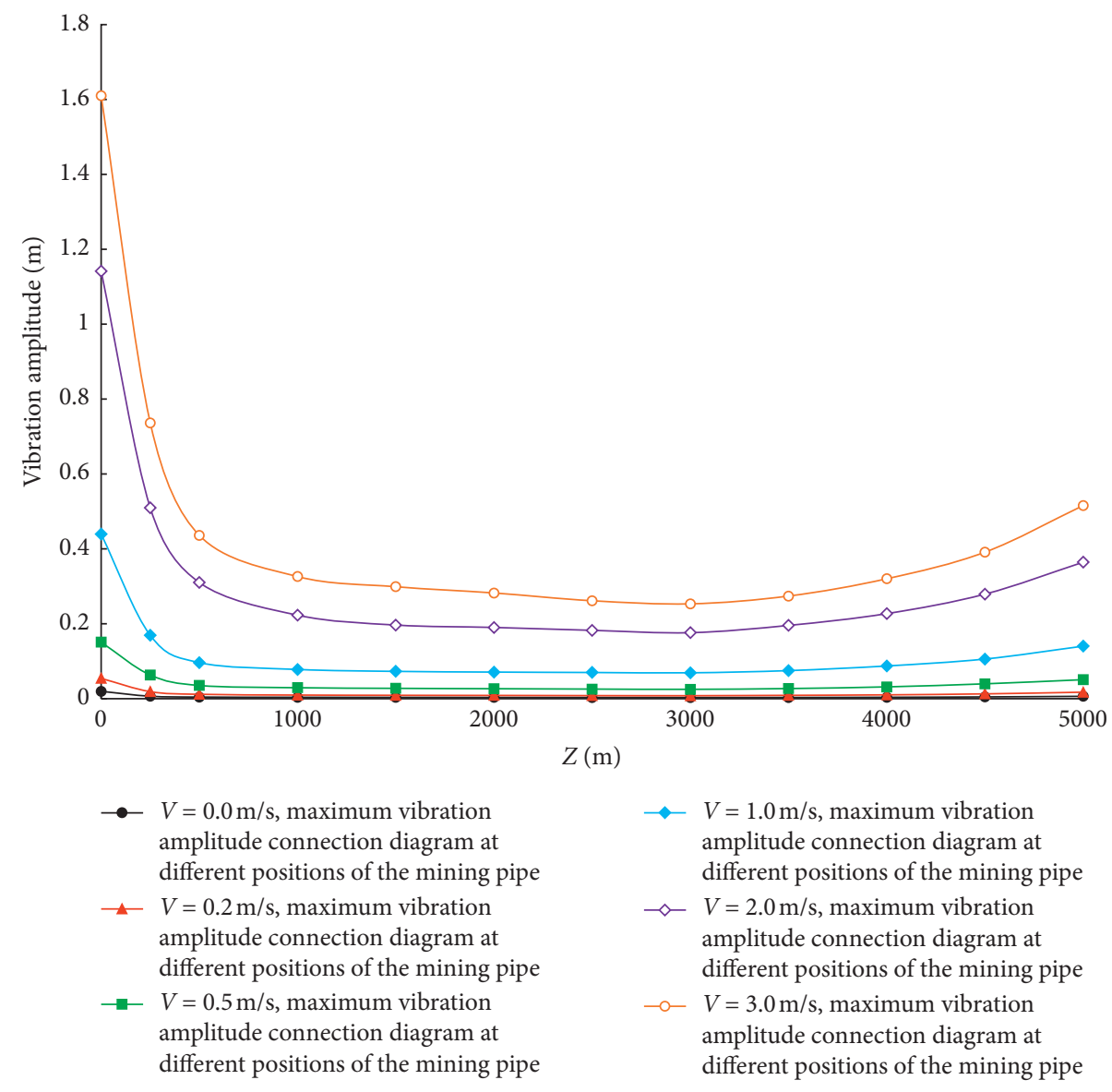

Figure 10: Variation diagram of maximum transverse vibration amplitude.

much larger than the transverse vibration amplitude; at this time, longitudinal vibration is the main vibration mode. When the towing velocity is greater than $3 \mathrm{~m} / \mathrm{s}$, the transverse vibration amplitude exceeds the longitudinal vibration amplitude; at this time, attention should be paid to the influence of transverse vibration on the mining pipe.

4.4. Vibration Analysis under Different Ore Bin Weights. When the towing velocity is $0.2 \mathrm{~m} / \mathrm{s}$, the damping is $200 \mathrm{~N} \cdot \mathrm{s} /$ $\mathrm{m}$, and the ore bin weight is $0 \mathrm{t}, 30 \mathrm{t}, 50 \mathrm{t}$, and $80 \mathrm{t}$, respectively. The pipe maximum vibration amplitude at different locations is shown in Figure 11.

As shown in Figure 11, increasing the ore bin weight will not change the pipe vibration trend, which decreases first and then increases, nor will it change the occurrence point of the minimum vibration value. However, increasing the ore bin weight will increase the overall longitudinal vibration amplitude and decrease the overall transverse vibration amplitude. This is because when the mining ship is towing at the low speed $(V=0.2 \mathrm{~m} / \mathrm{s})$, the amplitude of longitudinal vibration is much larger than that of transverse vibration. With the ore bin weight increase, the longitudinal inertia force and axial excitation are both increased, so the longitudinal vibration amplitude will increase. For the transverse vibration, with the ore bin weight increase, the mining pipe transverse excitation decreases, while the inertia force increases slightly, it is not enough to compensate for the decreased value, so the transverse vibration amplitude appears to be in the downward trend.

4.5. Vibration Analysis under Different Step Lengths. The total length of the mining pipe is $5000 \mathrm{~m}$, and the length of each step section of the mining pipe is, respectively, case 1, case 2, and case 3, and the specific values are shown in Table 4 . When the ore bin weight is $30 \mathrm{t}$, towing velocity is $0.2 \mathrm{~m} / \mathrm{s}$, and damping is $200 \mathrm{~N} \cdot \mathrm{s} / \mathrm{m}$, the pipe maximum vibration amplitude at different locations is shown in Figures 12 and 13.

As shown in Figures 12 and 13, changing the length of the mining pipe each step section cannot change the mining pipe vibration law, but it can change the position where the minimum vibration value appears. In case 1 , case 2 , and case 3 , the minimum longitudinal vibration amplitude appears at $1000 \mathrm{~m}, 1500 \mathrm{~m}$, and $2000 \mathrm{~m}$, and the minimum transverse vibration amplitude appears at $2500 \mathrm{~m}, 3000 \mathrm{~m}$, and $3500 \mathrm{~m}$, respectively. When the length of the first ladder section (large diameter section L1) is increased, the pipe overall vibration amplitude will decrease. The reason is because this stepped section pipeline diameter is large, strong force between nodes, the energy loss is large, and increasing the length of $L 1$ will increase the energy loss, so the vibration amplitude will decrease. On the contrary, when the $L 1$ length 


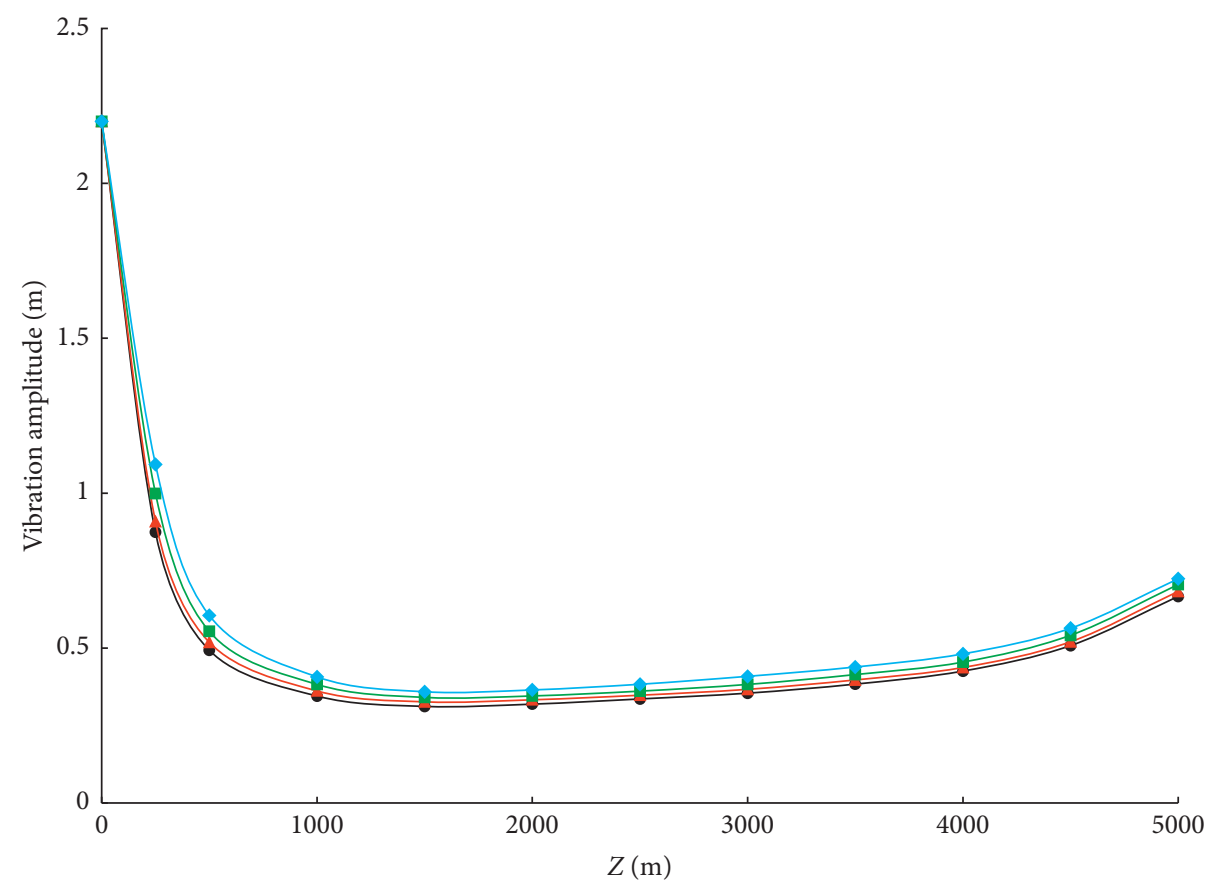

- $m=0$ t, maximum vibration amplitude connection diagram at different positions of the mining pipe

$\triangle m=30 \mathrm{t}$, maximum vibration amplitude connection diagram at different positions of the mining pipe

(a)
- $m=50 \mathrm{t}$, maximum vibration amplitude connection diagram at different positions of the mining pipe

$\rightarrow-m=80 \mathrm{t}$, maximum vibration amplitude connection diagram at different positions of the mining pipe

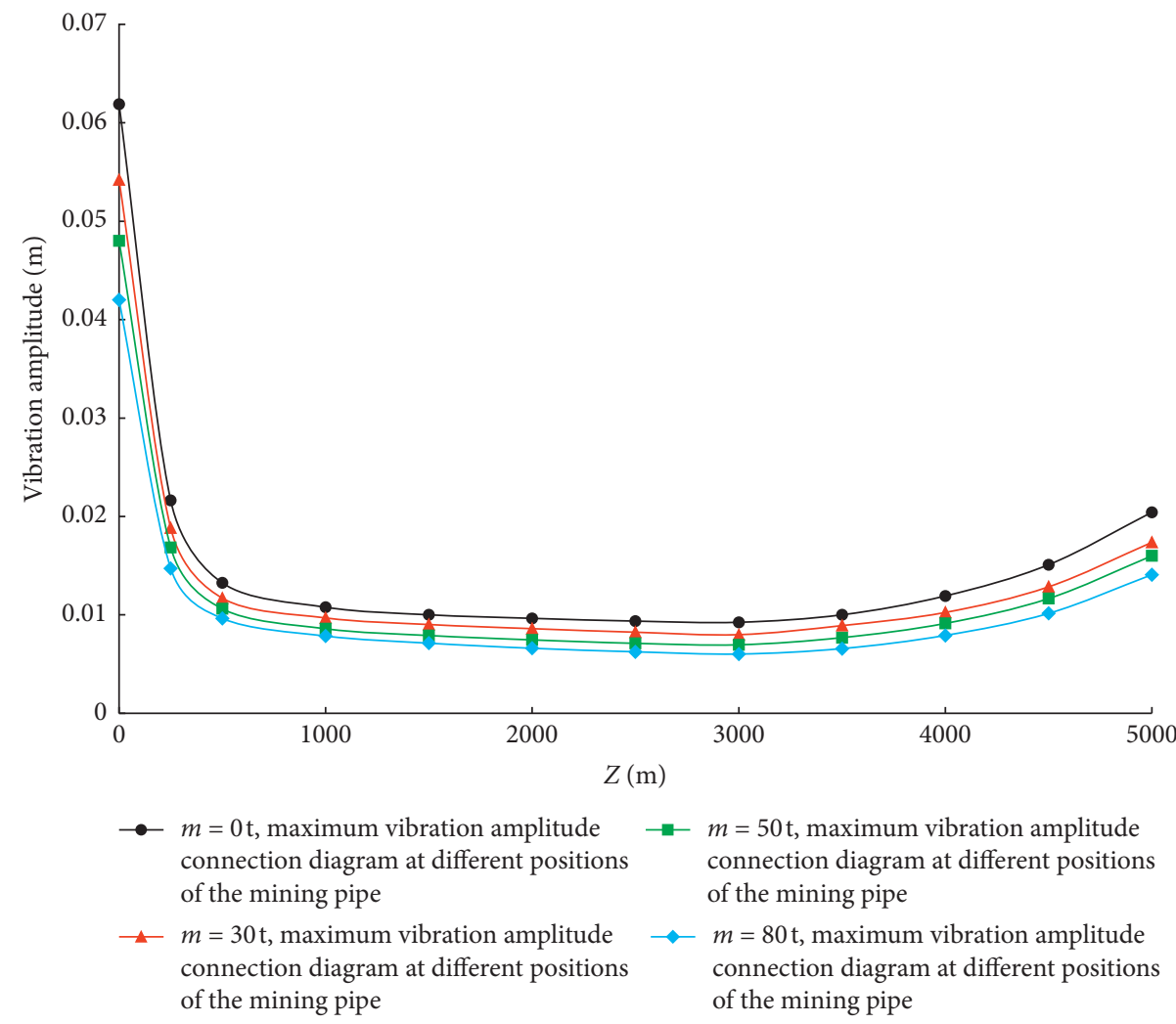

(b)

FIgURE 11: Variation diagram of maximum vibration amplitude under different ore bin weights. (a) Longitudinal. (b) Transverse. 
TABLE 4: Length of each step.

\begin{tabular}{lcccrr}
\hline Case & Ladder section & 1 & 2 & 3 & 4 \\
\hline 1 & $L(\mathrm{~m})$ & 500 & 1500 & 1500 & 1500 \\
2 & $L(\mathrm{~m})$ & 1000 & 1000 & 1500 & 1500 \\
3 & $L(\mathrm{~m})$ & 1500 & 1000 & 1000 & 1500 \\
\hline
\end{tabular}

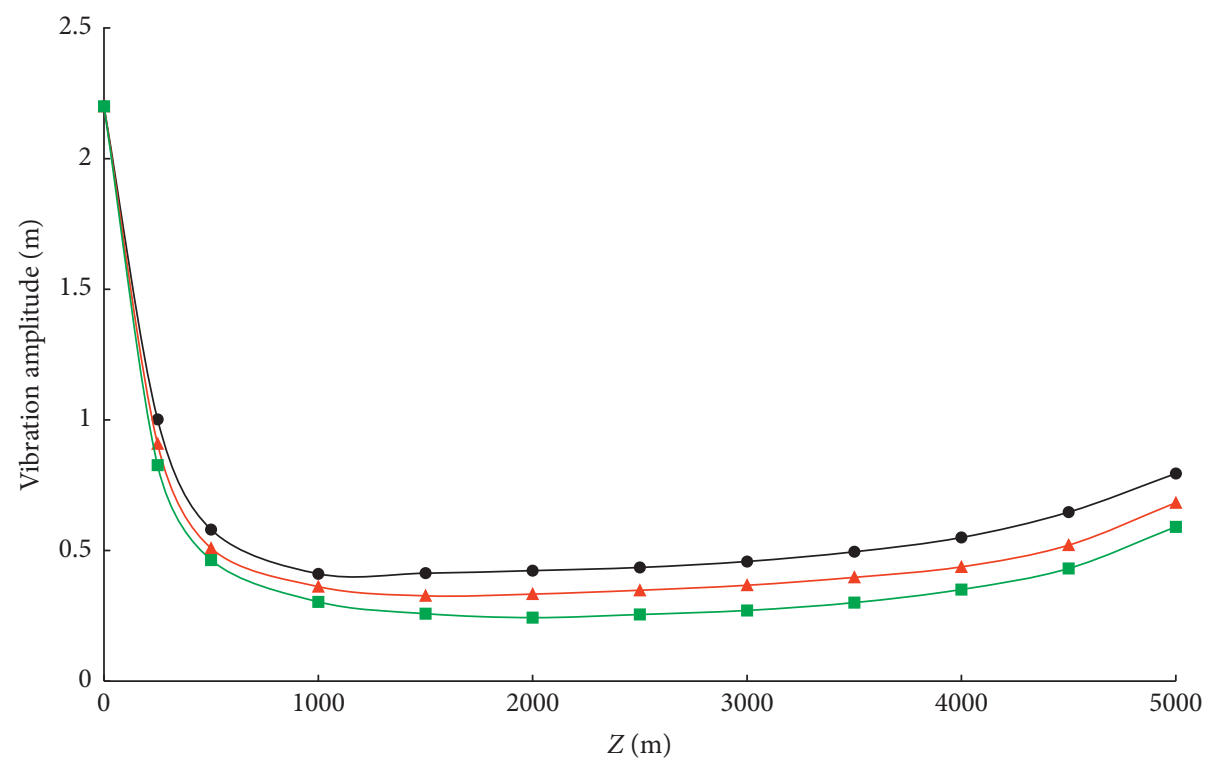

$\rightarrow$ Case 1, maximum vibration amplitude connection diagram at different positions of the mining pipe

$\triangle$ Case 2, maximum vibration amplitude connection diagram at different positions of the mining pipe

-- Case 3, maximum vibration amplitude connection diagram at different positions of the mining pipe

FIGURE 12: Variation diagram of maximum longitudinal vibration amplitude.

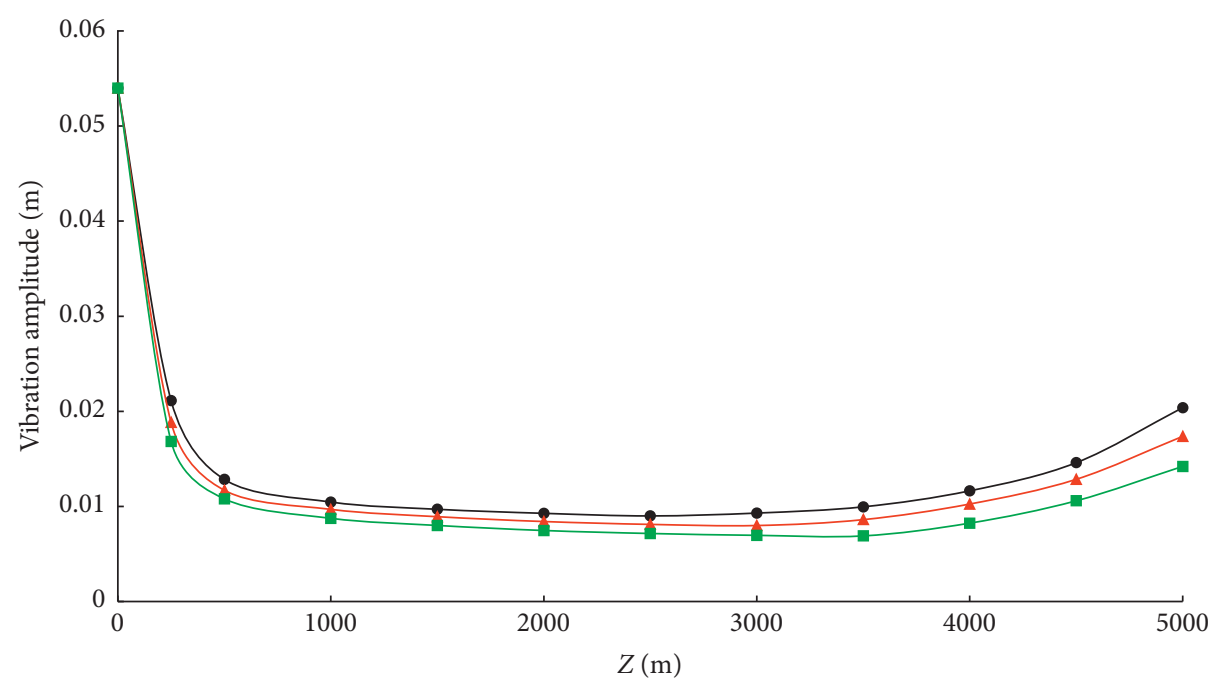

$\rightarrow$ Case 1, maximum vibration amplitude connection diagram at different positions of the mining pipe

\ Case 2, maximum vibration amplitude connection diagram at different positions of the mining pipe

$\rightarrow$ Case 3, maximum vibration amplitude connection diagram at different positions of the mining pipe

FIgURE 13: Variation diagram of maximum transverse vibration amplitude. 
is reduced, the mining pipe overall vibration amplitude will increase.

\subsection{Vibration Frequency Analysis}

(i) In case 2, when the ore bin weight is $30 \mathrm{t}$, the towing velocity is $0 \mathrm{~m} / \mathrm{s}, 0.2 \mathrm{~m} / \mathrm{s}, 0.5 \mathrm{~m} / \mathrm{s}, 1.0 \mathrm{~m} / \mathrm{s}, 2.0 \mathrm{~m} / \mathrm{s}$, and $3.0 \mathrm{~m} / \mathrm{s}$, and the damping is $200 \mathrm{~N} \cdot \mathrm{s} / \mathrm{m}$; the mining pipe vibration frequency is shown in Figures 14 and 15 .

As shown in Figures 14 and 15, increasing the towing velocity will decrease the longitudinal vibration intensity and increase the transverse vibration intensity. However, the vibration frequency of the mining pipe does not change with the change of towing velocities. At the first-order vibration frequency, the maximum longitudinal and transverse vibration intensity occurs, and when the towing velocity is less than $2 \mathrm{~m} / \mathrm{s}$, the longitudinal vibration intensity is greater than the transverse vibration intensity.

(ii) In case 2, when the ore bin weight is $0 \mathrm{t}, 30 \mathrm{t}, 50 \mathrm{t}$, and $80 \mathrm{t}$, towing velocity is $0.2 \mathrm{~m} / \mathrm{s}$ and damping is $200 \mathrm{~N} \cdot \mathrm{s} / \mathrm{m}$; the vibration frequency is shown in Figures 16 and 17.

It can be seen from Figures 16 and 17 that increasing the ore bin weight will increase the intensity of longitudinal vibration and decrease the intensity of transverse vibration, but the change of the ore bin weight will not change the vibration frequency. When the mining ship is sailing at the low velocity $(V=0.2 \mathrm{~m} / \mathrm{s})$, the intensity of longitudinal vibration is much greater than that of transverse vibration; at this time, the intensity of longitudinal vibration is mainly reduced.

(iii) The length of the step section is case 1, case 2, and case 3 , respectively. When the ore bin weight is $30 \mathrm{t}$, the towing velocity is $0.2 \mathrm{~m} / \mathrm{s}$ and the damping is $200 \mathrm{~N} \cdot \mathrm{s} / \mathrm{m}$; the vibration frequency is shown in Figures 18 and 19.

As shown in Figures 18 and 19, under the condition that the mining pipe total length is unchanged, changing the length of each step section can make the vibration intensity and vibration frequency change, and increasing the $L 1$ length can reduce the vibration intensity and vibration frequency, but the maximum value of longitudinal and transverse vibration intensity still appears at the first-order vibration frequency. However, when the towing velocity is $0.2 \mathrm{~m} / \mathrm{s}$, no matter how the length of the mining pipe each step section changes, the intensity of the longitudinal vibration is much greater than that of the transverse vibration. At this time, the longitudinal vibration is still the main vibration mode. (iv) Under the case 2, taking the first four order vibration frequencies for research, the corresponding longitudinal vibration frequencies were $11.57 \mathrm{~Hz}$, $12.45 \mathrm{~Hz}, 13.33 \mathrm{~Hz}$, and $13.82 \mathrm{~Hz}$, respectively; the corresponding transverse vibration frequencies were $0.023 \mathrm{~Hz}, 0.0249 \mathrm{~Hz}, 0.0267 \mathrm{~Hz}$, and $0.0276 \mathrm{~Hz}$, respectively. The distance between the vibration frequency and the natural frequency nearest to itself: the first-order vibration frequency is closest to the natural frequency, followed the third-order, then the fourth-order, and finally the second-order, which is the farthest away from the natural frequency.

(1) When the ore bin weight is $30 \mathrm{t}$, the towing velocity is $0.2 \mathrm{~m} / \mathrm{s}$, and the damping is $0 \mathrm{~N} \cdot \mathrm{s} / \mathrm{m}$ and $200 \mathrm{~N} \cdot \mathrm{s} / \mathrm{m}$; the variation diagram of vibration intensity is shown in Figures 20 and 21.

In Figures 20 and 21, when the towing velocity is $0.2 \mathrm{~m} / \mathrm{s}$ and the damping increases from $0 \mathrm{~N} \cdot \mathrm{s} / \mathrm{m}$ to $200 \mathrm{~N} \cdot \mathrm{s} / \mathrm{m}$, the longitudinal and transverse vibration intensity will attenuate to different degrees; the specific values are shown in Table 5. According to data analysis, whether it is longitudinal or transverse vibration, the vibration intensity at the first-order vibration frequency is the largest, followed the third-order, then the fourth-order, and finally the second-order vibration frequency, which has the lowest vibration intensity. After adding damping, the amplitude of vibration intensity reduction at the first-order frequency is the largest, and the amplitude decrease at the second-order is the smallest. It indicates that the closer the vibration frequency is to the natural frequency, the greater the vibration intensity is, after adding damping, the greater the vibration attenuation degree is, and the more obvious the vibration reduction effect is. In addition, comparing Figures 20 and 21 , it can be found that the longitudinal vibration intensity is much greater than the transverse vibration intensity at this time. When the same damping is added, the attenuation value of the longitudinal vibration intensity is large, and the vibration reduction effect is obvious, but the longitudinal vibration intensity after adding damping is still far greater than the intensity of transverse vibration without damping. It shows that when the towing velocity is $0.2 \mathrm{~m} / \mathrm{s}$, the longitudinal vibration is the main vibration mode, and the longitudinal vibration is mainly processed in the vibration reduction control.

(2) When the ore bin weight is $30 \mathrm{t}$, the towing velocity is $2.8 \mathrm{~m} / \mathrm{s}$, and the damping is $0 \mathrm{~N} \cdot \mathrm{s} / \mathrm{m}$ and $200 \mathrm{~N} \cdot \mathrm{s} / \mathrm{m}$; the variation diagram of vibration intensity is shown in Figures 22 and 23. 


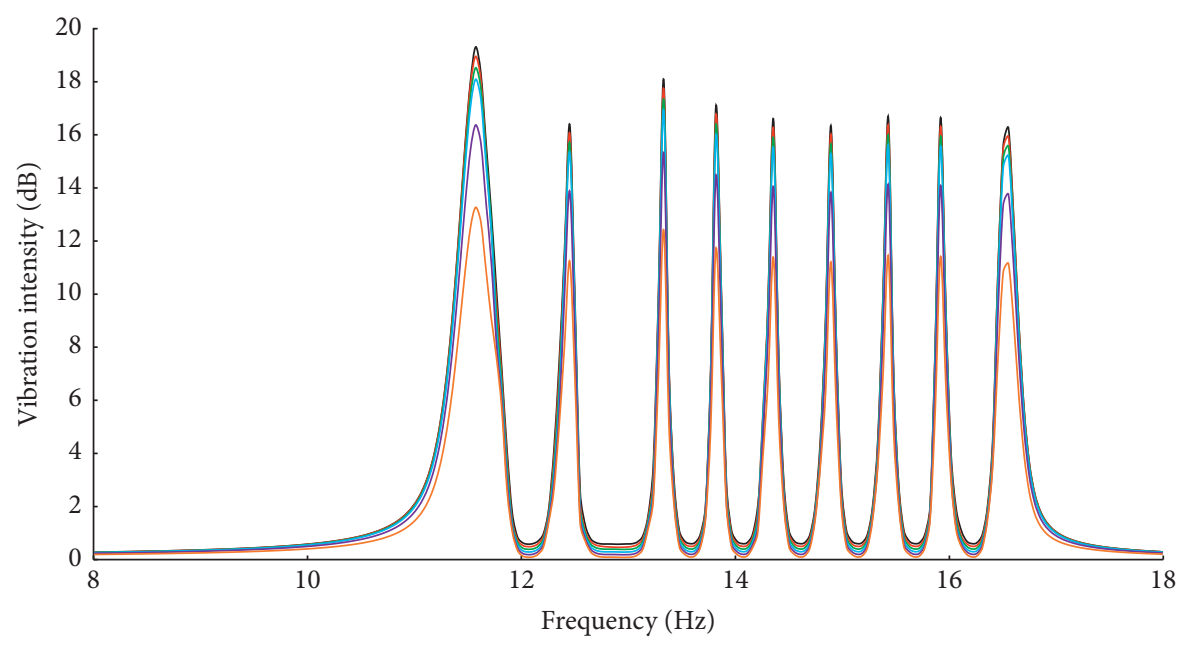

- $V=0.0 \mathrm{~m} / \mathrm{s}$, longitudinal vibration frequency of the mining pipe

- $V=0.2 \mathrm{~m} / \mathrm{s}$, longitudinal vibration frequency of the mining pipe

$V=0.5 \mathrm{~m} / \mathrm{s}$, longitudinal vibration frequency of the mining pipe

$V=1.0 \mathrm{~m} / \mathrm{s}$, longitudinal vibration frequency of the mining pipe

- $V=2.0 \mathrm{~m} / \mathrm{s}$, longitudinal vibration frequency of the mining pipe

- $V=3.0 \mathrm{~m} / \mathrm{s}$, longitudinal vibration frequency of the mining pipe

Figure 14: Longitudinal vibration frequency under different towing velocities.

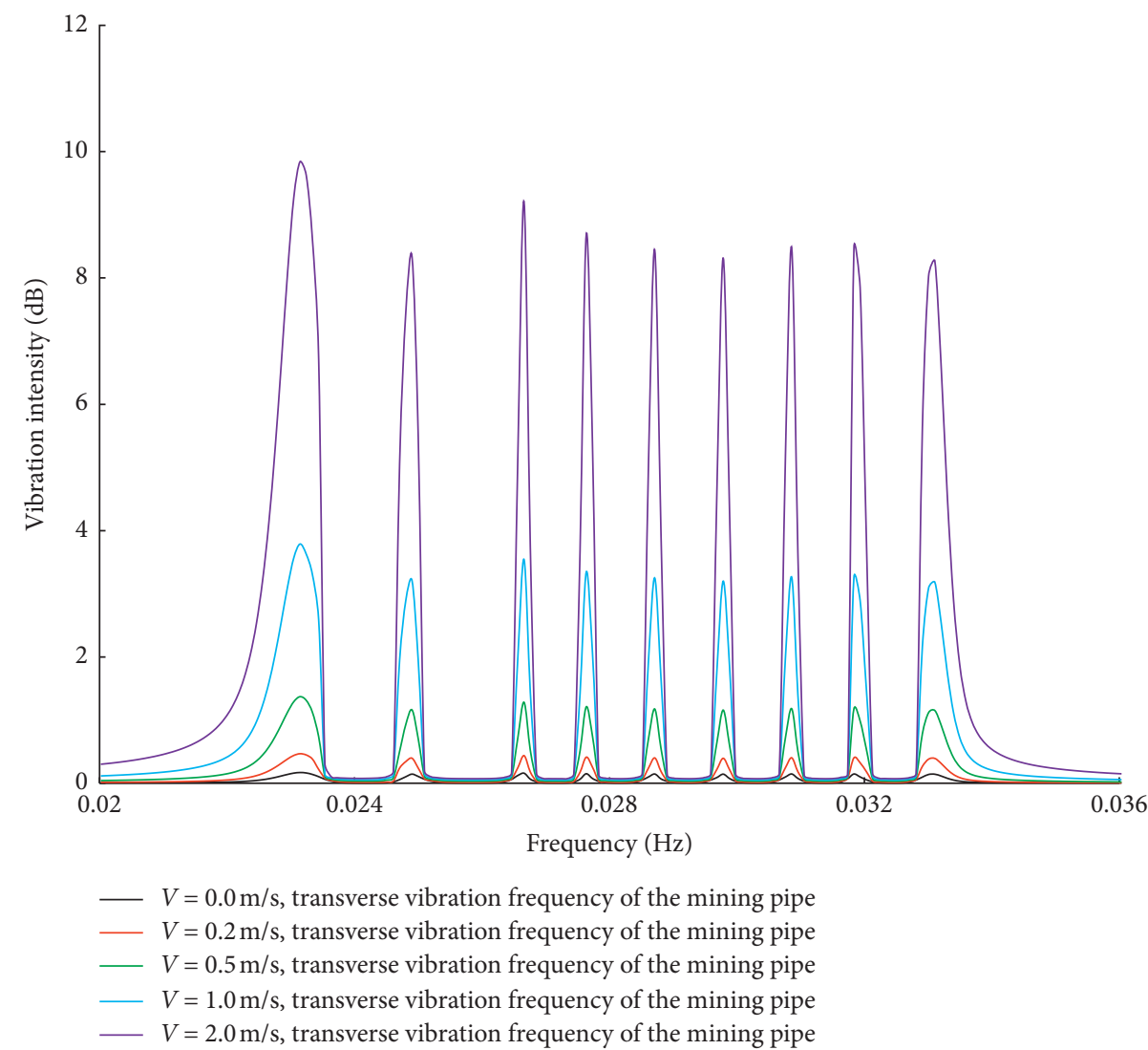

FIgURE 15: Transverse vibration frequency under different towing velocities. 


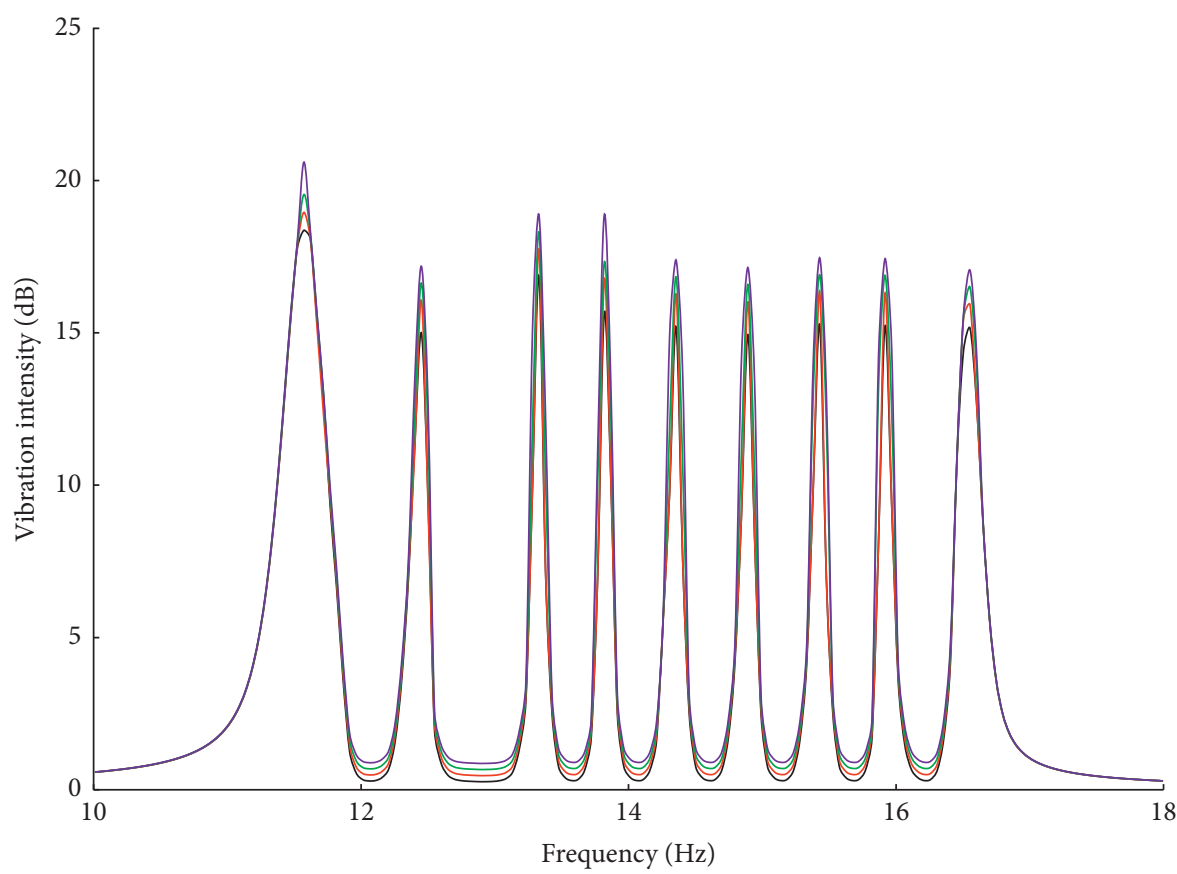
$m=0 \mathrm{t}$, longitudinal vibration frequency $-m=50 \mathrm{t}$, longitudinal vibration frequency of the mining pipe of the mining pipe
$-m=30 \mathrm{t}$, longitudinal vibration frequency $-m=80 \mathrm{t}$, longitudinal vibration frequency of the mining pipe of the mining pipe

FIgURE 16: Longitudinal vibration frequency.

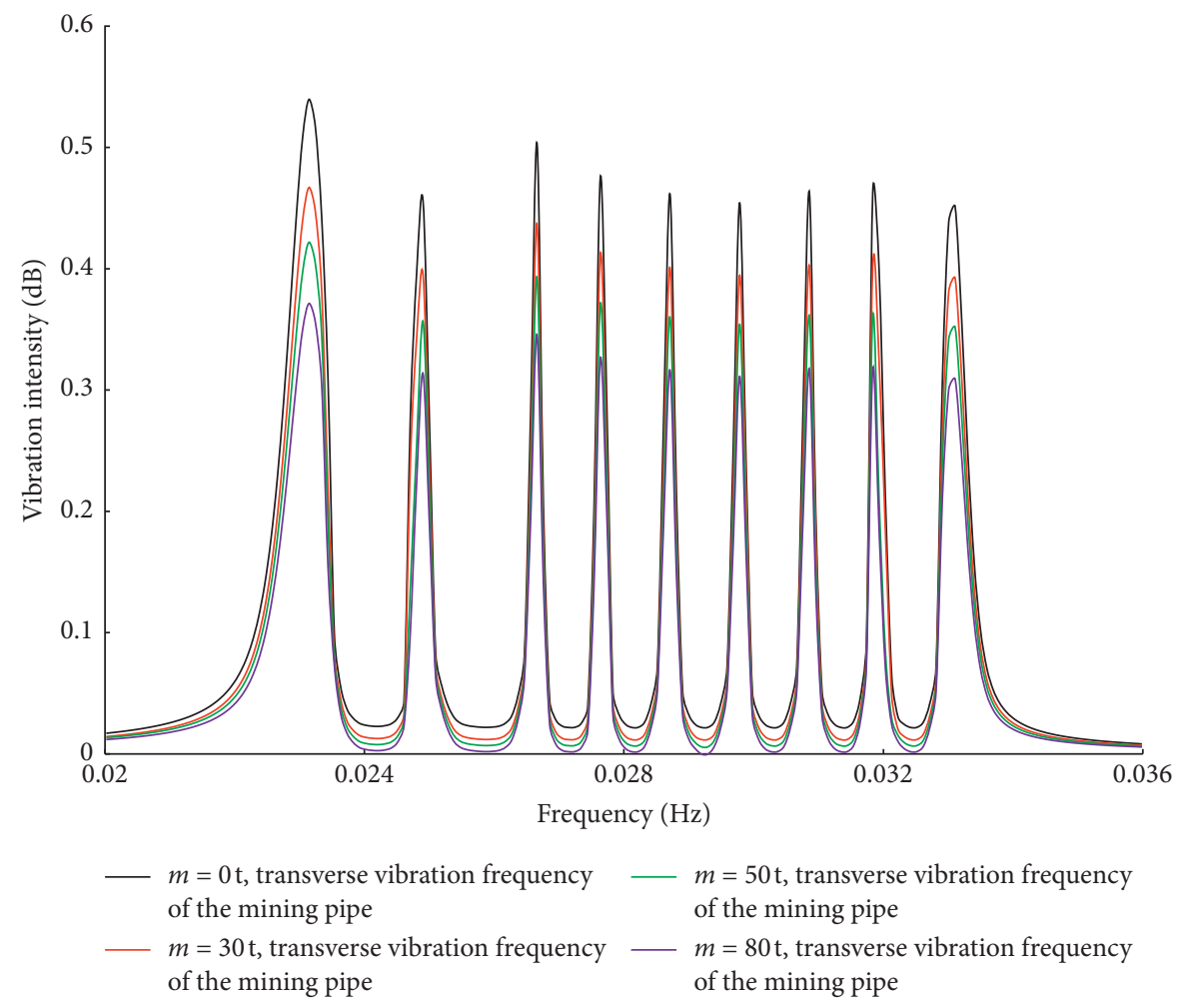

FIgURE 17: Transverse vibration frequency. 


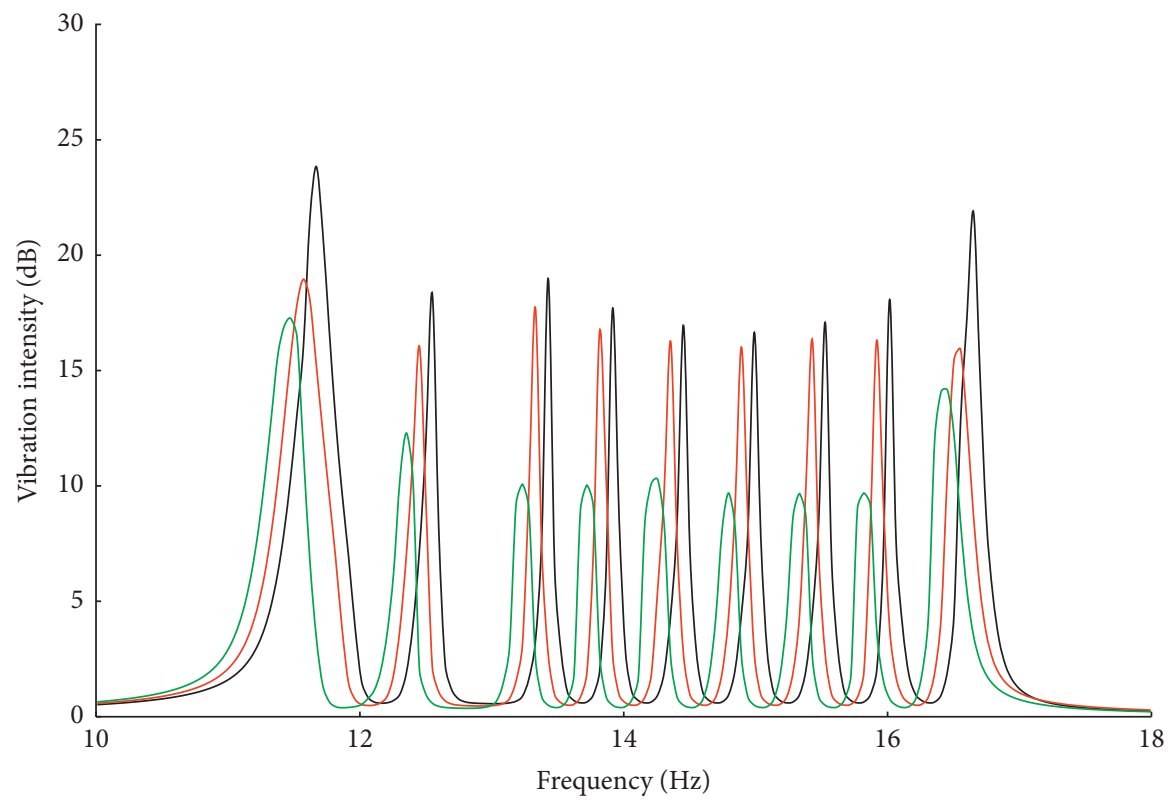

- Case 1, longitudinal vibration frequency of the mining pipe Case 2, longitudinal vibration frequency of the mining pipe

_ Case 3, longitudinal vibration frequency of the mining pipe

FIgURE 18: Longitudinal vibration frequency.

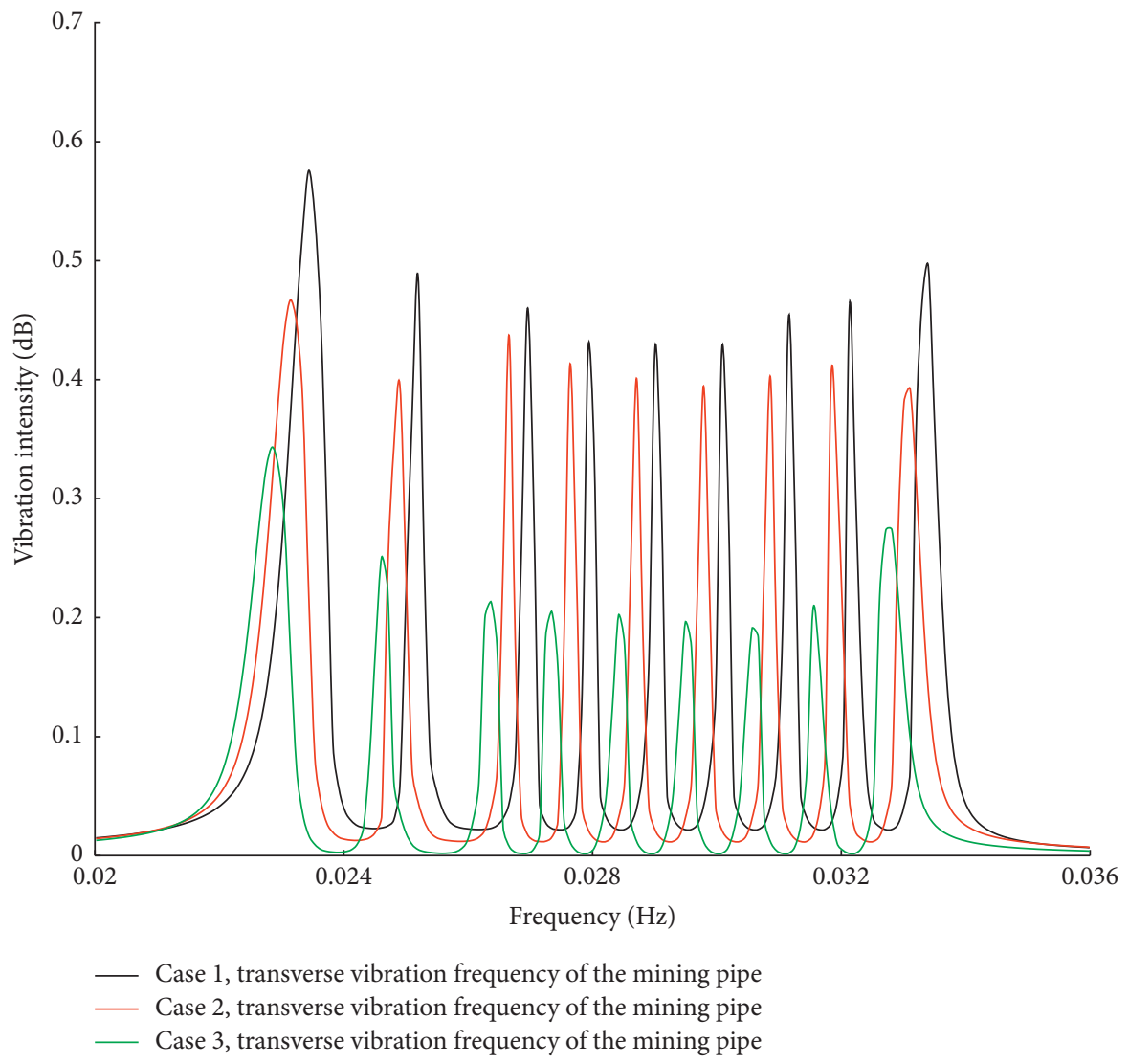

Figure 19: Transverse vibration frequency. 


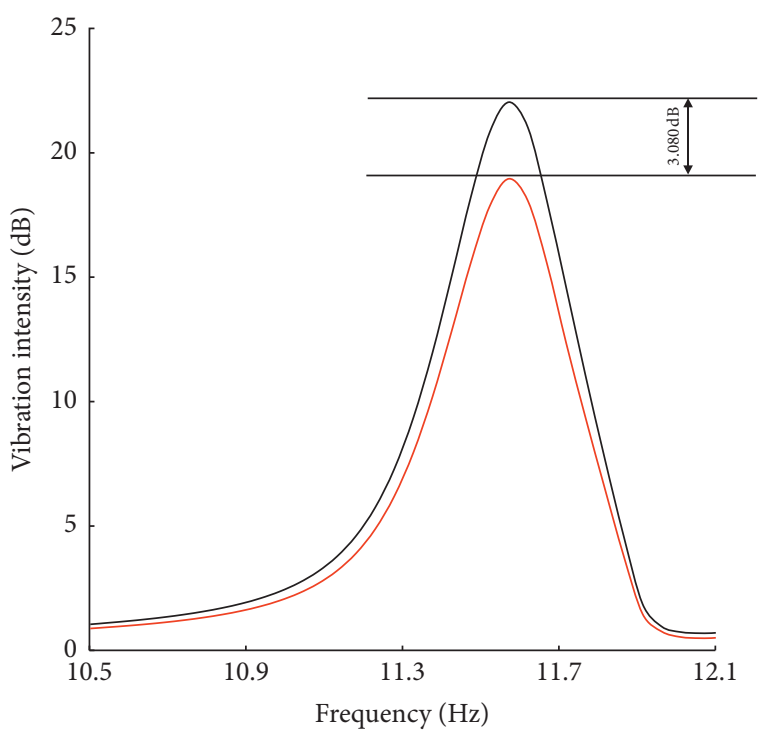

$c=0 \mathrm{~N} \cdot \mathrm{s} / \mathrm{m}$, vibration intensity of the mining pipe - $c=200 \mathrm{~N} \cdot \mathrm{s} / \mathrm{m}$, vibration intensity of the mining pipe

(a)

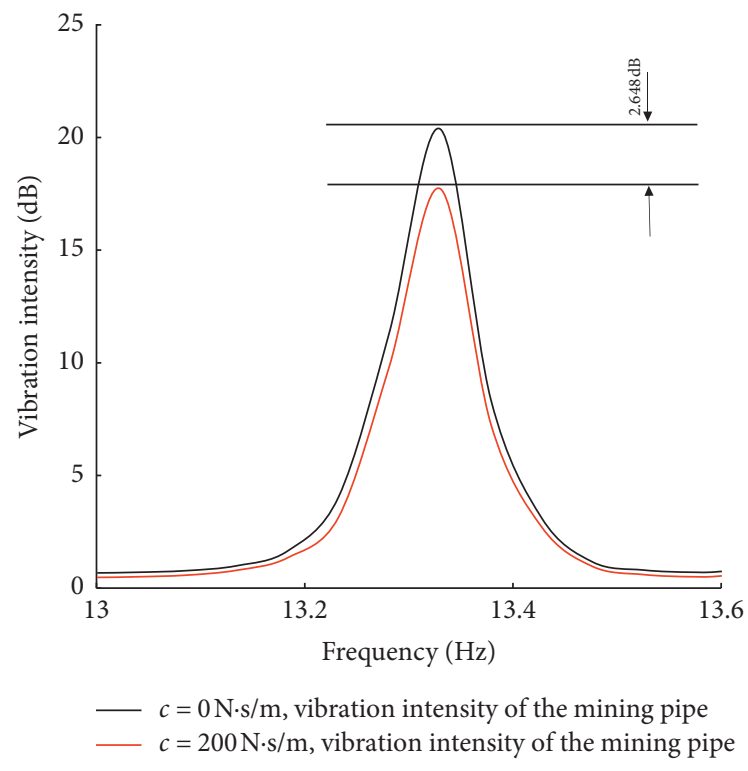

(c)

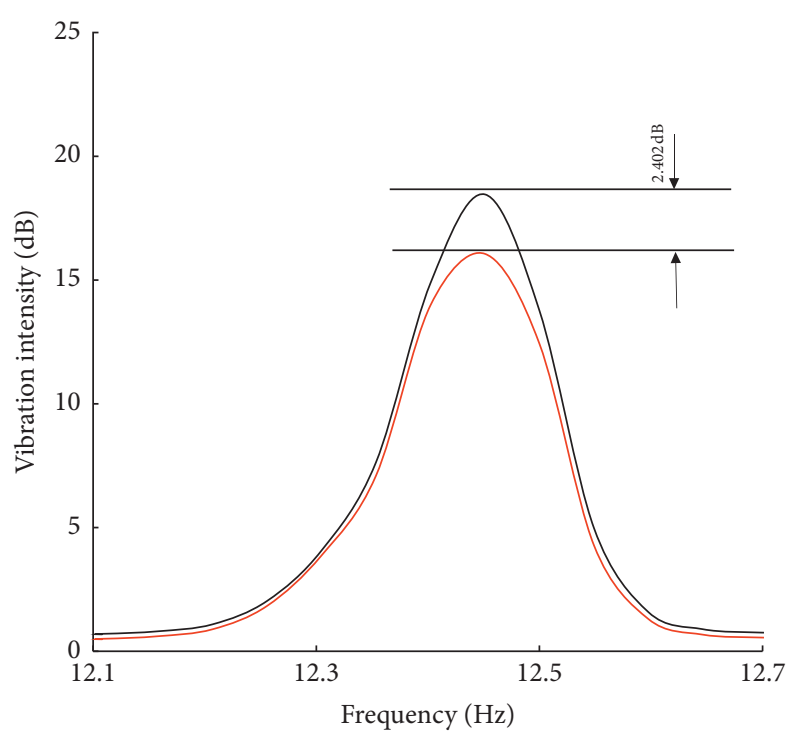

$c=0 \mathrm{~N} \cdot \mathrm{s} / \mathrm{m}$, vibration intensity of the mining pipe
$c-200 \mathrm{~N} \cdot \mathrm{s} / \mathrm{m}$, vibration intensity of the mining pipe

(b)

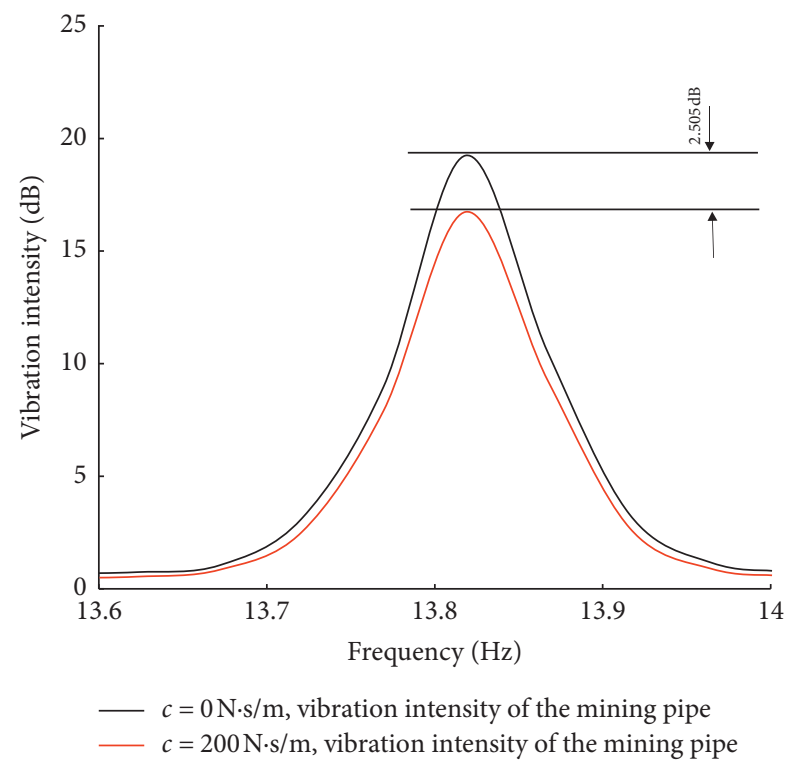

(d)

FIgURE 20: $V=0.2 \mathrm{~m} / \mathrm{s}$. Variation diagram of longitudinal vibration intensity. (a) First-order. (b) Second-order. (c) Third-order. (d) Fourthorder.

In Figures 22 and 23, when the towing velocity is $2.8 \mathrm{~m} / \mathrm{s}$, increasing the damping will reduce the vibration intensity; the specific values are shown in Table 6. It can be seen from the data in Table 6 that there is little difference between the longitudinal and transverse vibration intensities at this time. After damping is added, the attenuation value of the vibration intensity is almost the same. This indicates that when the towing velocity is $2.8 \mathrm{~m} / \mathrm{s}$, the longitudinal and transverse vibrations are the same and both have strong vibration intensity; therefore, attention should be paid to both the transverse and longitudinal vibrations during the vibration reduction control.

(3) When the ore bin weight is $30 t$, the towing velocity is $3.0 \mathrm{~m} / \mathrm{s}$, and the damping is $0 \mathrm{~N} \cdot \mathrm{s} / \mathrm{m}$ and $200 \mathrm{~N} \cdot \mathrm{s} / \mathrm{m}$; the variation diagram of vibration intensity is shown in Figures 24 and 25. As shown in Figures 24 and 25, when the towing velocity is $3.0 \mathrm{~m} / \mathrm{s}$ and the damping is increased from $0 \mathrm{~N} \cdot \mathrm{s} / \mathrm{m}$ to $200 \mathrm{~N} \cdot \mathrm{s} / \mathrm{m}$, the longitudinal and transverse vibration intensity will also be attenuated; the specific values are shown in 


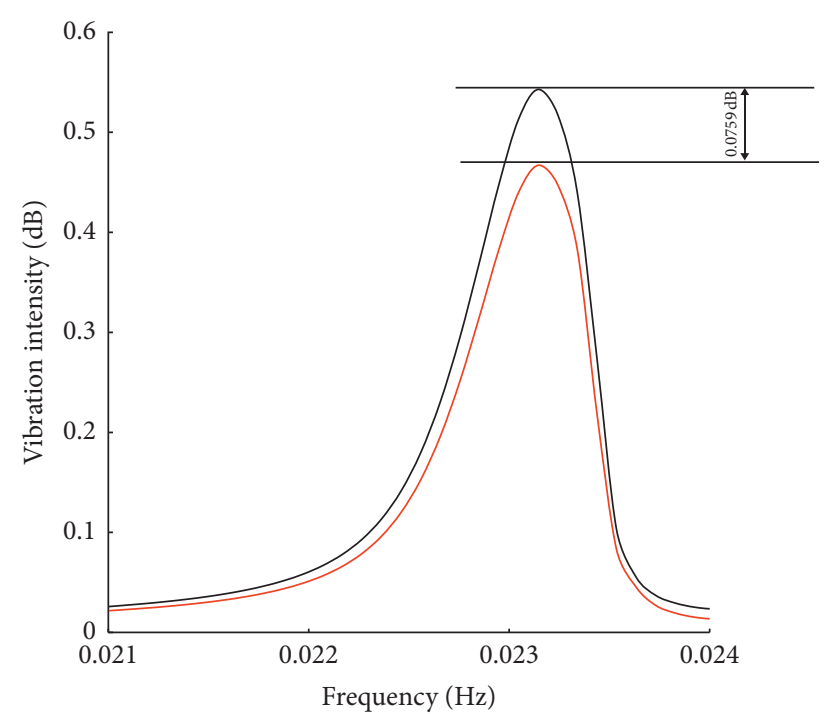

$c=0 \mathrm{~N} \cdot \mathrm{s} / \mathrm{m}$, vibration intensity of the mining pipe $c=200 \mathrm{~N} \cdot \mathrm{s} / \mathrm{m}$, vibration intensity of the mining pipe

(a)

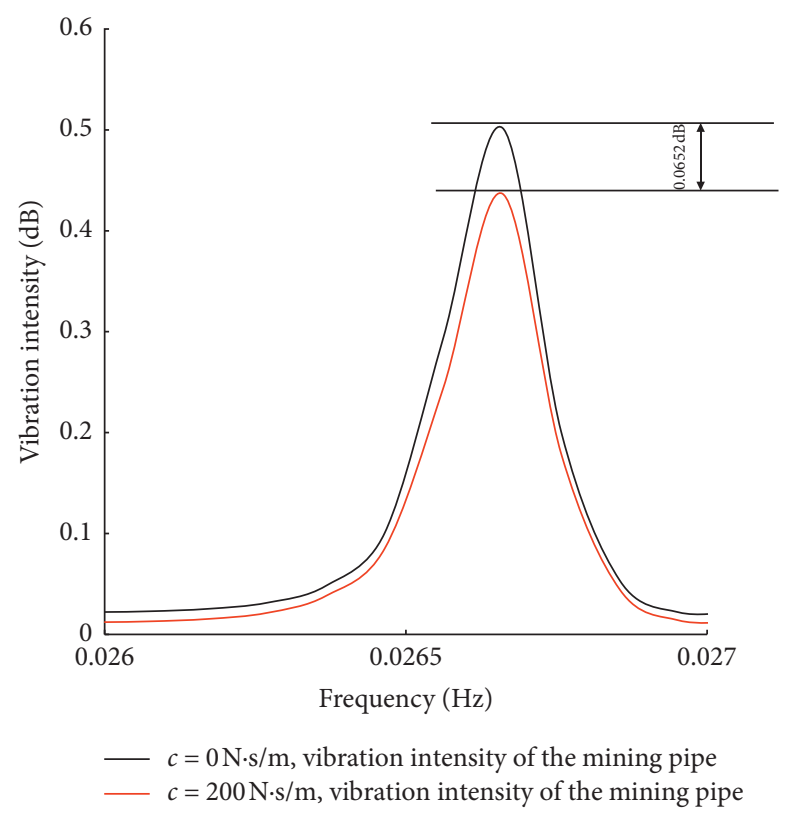

(c)

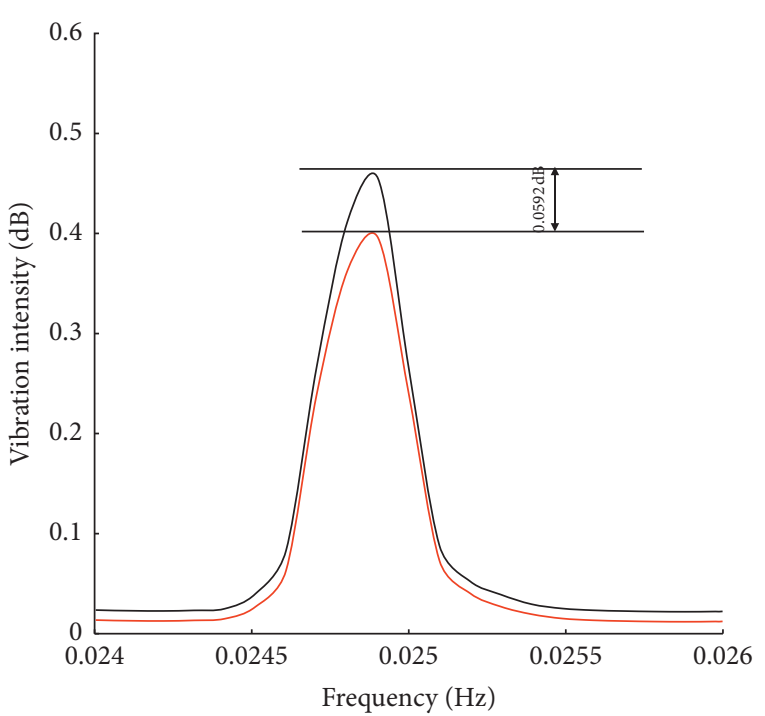

$-c=0 \mathrm{~N} \cdot \mathrm{s} / \mathrm{m}$, vibration intensity of the mining pipe $c=200 \mathrm{~N} \cdot \mathrm{s} / \mathrm{m}$, vibration intensity of the mining pipe

(b)

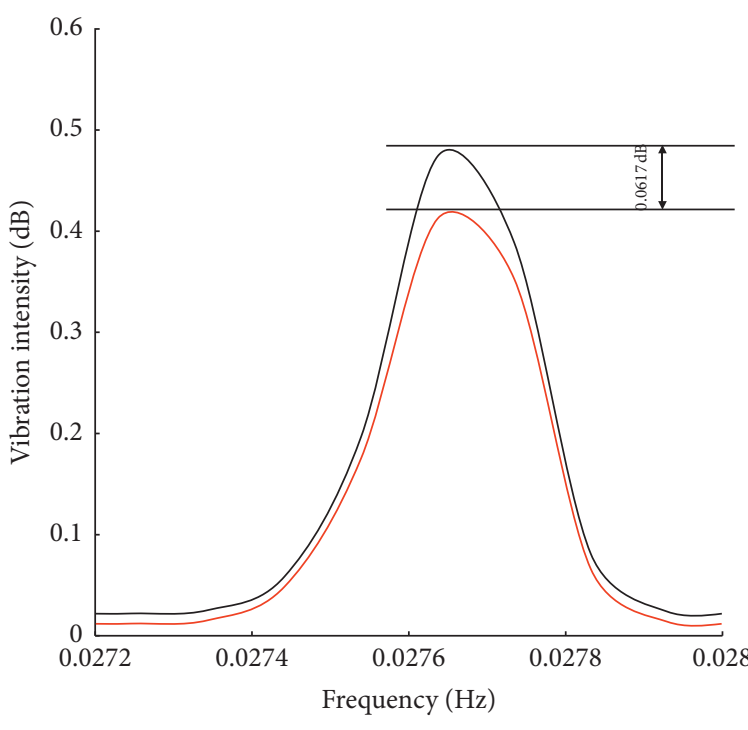

- $c=0 \mathrm{~N} \cdot \mathrm{s} / \mathrm{m}$, vibration intensity of the mining pipe $c=200 \mathrm{~N} \cdot \mathrm{s} / \mathrm{m}$, vibration intensity of the mining pipe

(d)

FIgURE 21: $V=0.2 \mathrm{~m} / \mathrm{s}$. Variation diagram of transverse vibration intensity. (a) First-order. (b) Second-order. (c) Third-order. (d) Fourthorder.

TABLE 5: Vibration data statistics table.

\begin{tabular}{|c|c|c|c|c|c|c|c|}
\hline \multicolumn{4}{|c|}{ Longitudinal } & \multicolumn{4}{|c|}{ Transverse } \\
\hline $\begin{array}{l}\text { Vibration } \\
\text { frequency } \\
\text { order number }\end{array}$ & $\begin{array}{c}c=0 \mathrm{~N} \cdot \mathrm{s} / \mathrm{m}, \\
\text { vibration } \\
\text { intensity }(\mathrm{dB})\end{array}$ & $\begin{array}{c}c=200 \mathrm{~N} \cdot \mathrm{s} / \mathrm{m}, \\
\text { vibration } \\
\text { intensity }(\mathrm{dB})\end{array}$ & $\begin{array}{l}\text { Attenuation value } \\
\qquad(\mathrm{dB})\end{array}$ & $\begin{array}{c}\text { Vibration } \\
\text { frequency } \\
\text { order number }\end{array}$ & $\begin{array}{c}c=0 \mathrm{~N} \cdot \mathrm{s} / \mathrm{m}, \\
\text { vibration } \\
\text { intensity } \\
(\mathrm{dB})\end{array}$ & $\begin{array}{c}c=200 \mathrm{~N} \cdot \mathrm{s} / \\
\mathrm{m}, \\
\text { vibration } \\
\text { intensity } \\
(\mathrm{dB})\end{array}$ & $\begin{array}{l}\text { Attenuation value } \\
\text { (dB) }\end{array}$ \\
\hline 1 & 22.036 & 18.956 & 3.080 & 1 & 0.5429 & 0.4670 & 0.0759 \\
\hline 2 & 18.459 & 16.057 & 2.402 & 2 & 0.4548 & 0.3956 & 0.0592 \\
\hline 3 & 20.378 & 17.730 & 2.648 & 3 & 0.5020 & 0.4368 & 0.0652 \\
\hline 4 & 19.244 & 16.739 & 2.505 & 4 & 0.4741 & 0.4124 & 0.0617 \\
\hline
\end{tabular}




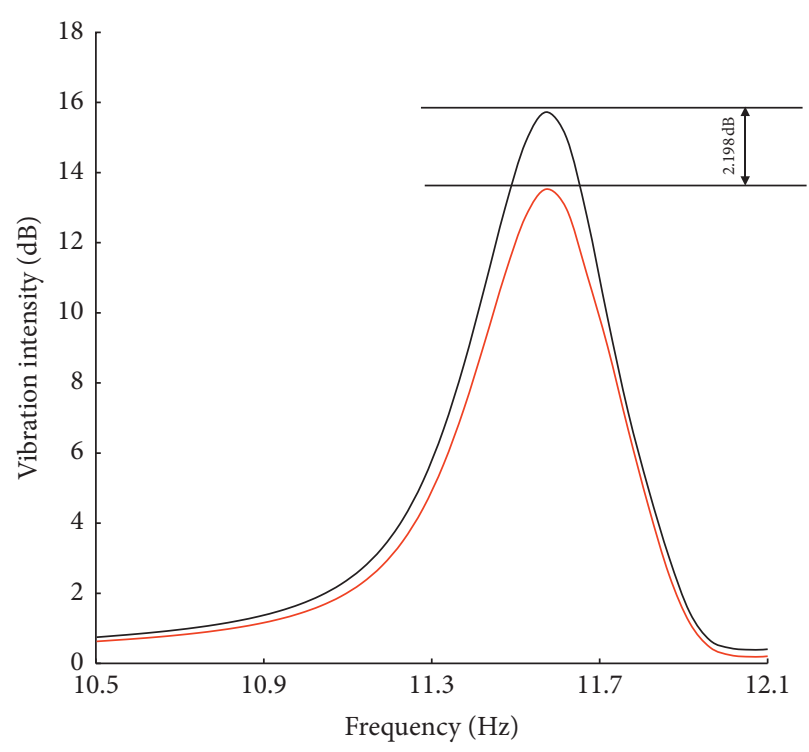

$c=0 \mathrm{~N} \cdot \mathrm{s} / \mathrm{m}$, vibration intensity of the mining pipe $c=200 \mathrm{~N} \cdot \mathrm{s} / \mathrm{m}$, vibration intensity of the mining pipe

(a)

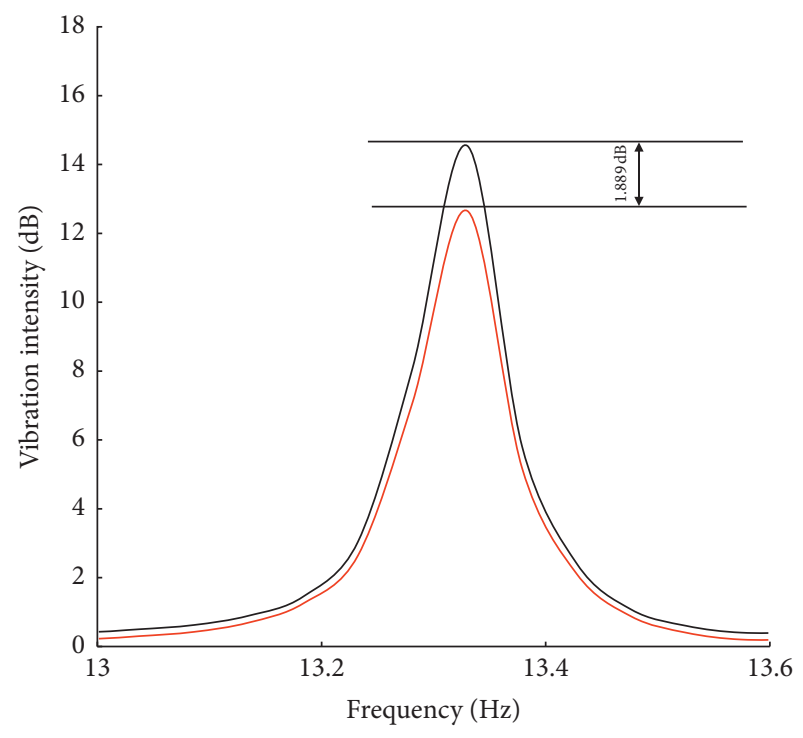

$c=0 \mathrm{~N} \cdot \mathrm{s} / \mathrm{m}$, vibration intensity of the mining pipe $c=200 \mathrm{~N} \cdot \mathrm{s} / \mathrm{m}$, vibration intensity of the mining pipe

(c)

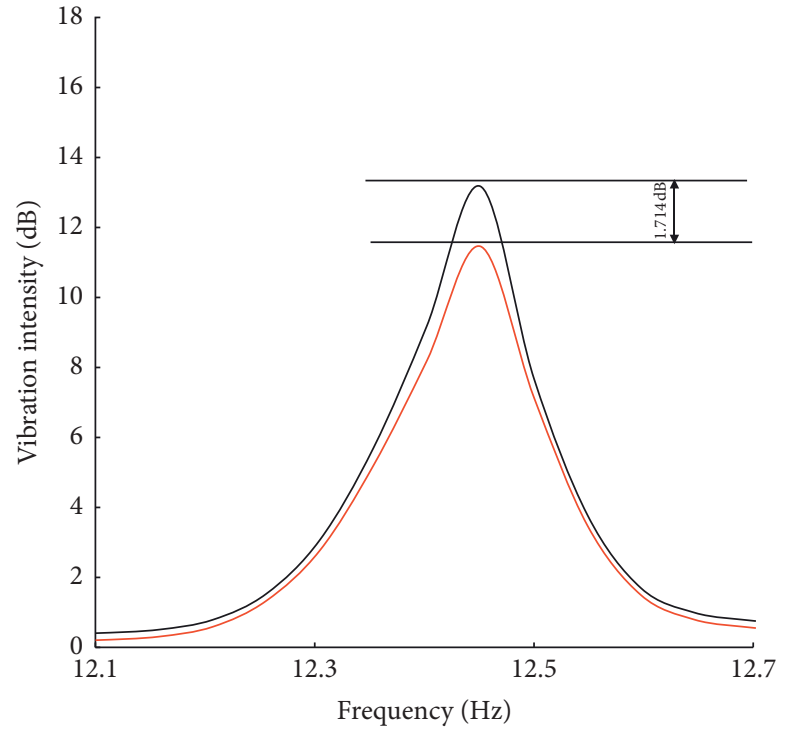

$c=0 \mathrm{~N} \cdot \mathrm{s} / \mathrm{m}$, vibration intensity of the mining pipe $c=200 \mathrm{~N} \cdot \mathrm{s} / \mathrm{m}$, vibration intensity of the mining pipe

(b)

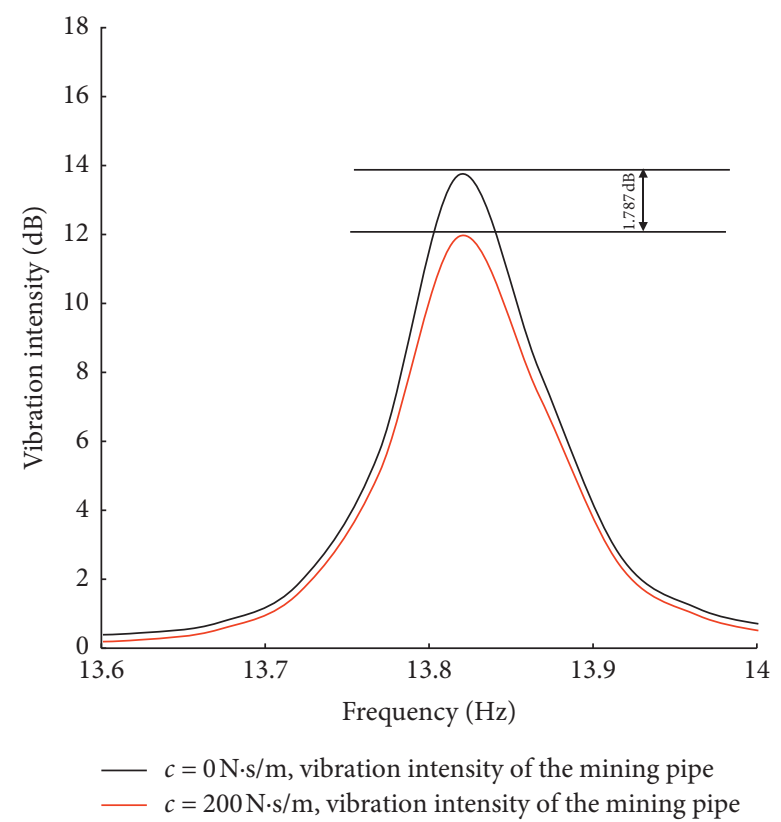

(d)

FIGURE 22: $V=2.8 \mathrm{~m} / \mathrm{s}$. Variation diagram of longitudinal vibration intensity. (a) First-order. (b) Second-order. (c) Third-order. (d) Fourthorder. 


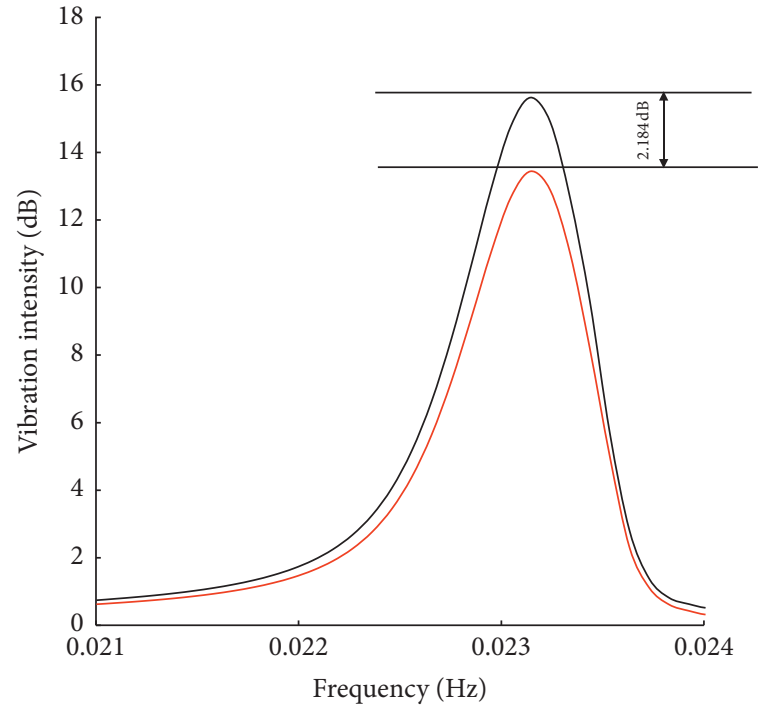

$c=0 \mathrm{~N} \cdot \mathrm{s} / \mathrm{m}$, vibration intensity of the mining pipe $c=200 \mathrm{~N} \cdot \mathrm{s} / \mathrm{m}$, vibration intensity of the mining pipe

(a)

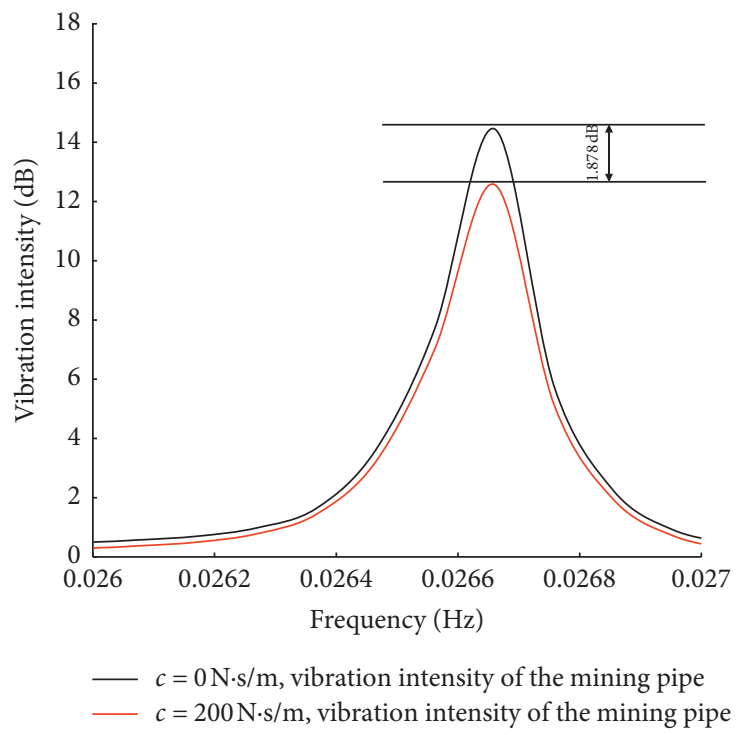

(c)

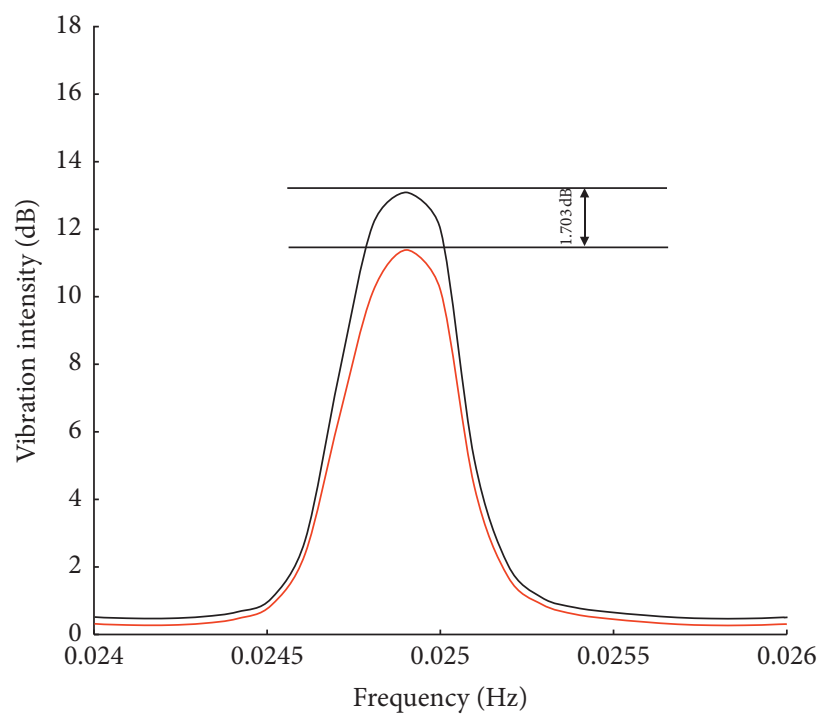

$c=0 \mathrm{~N} \cdot \mathrm{s} / \mathrm{m}$, vibration intensity of the mining pipe - $c=200 \mathrm{~N} \cdot \mathrm{s} / \mathrm{m}$, vibration intensity of the mining pipe

(b)

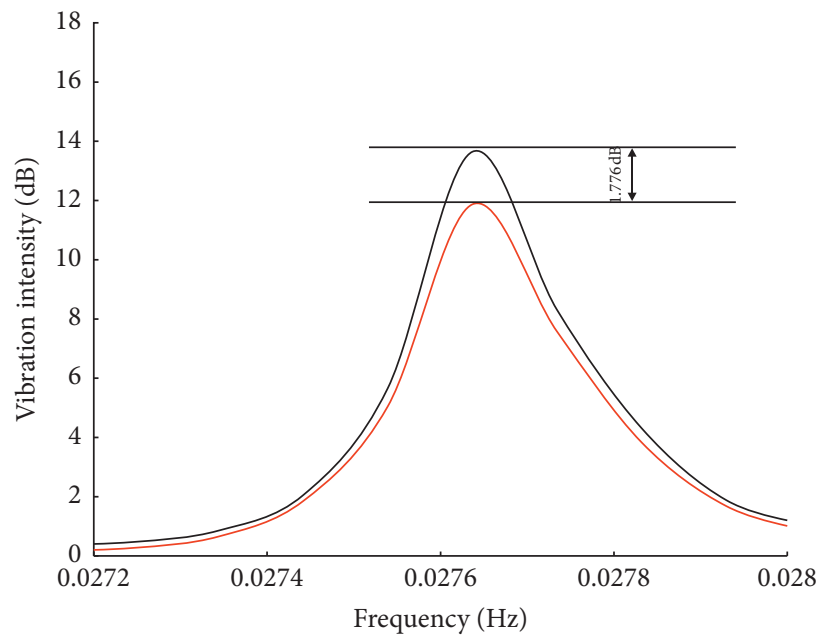

- $c=0 \mathrm{~N} \cdot \mathrm{s} / \mathrm{m}$, vibration intensity of the mining pipe $c=200 \mathrm{~N} \cdot \mathrm{s} / \mathrm{m}$, vibration intensity of the mining pipe

(d)

Figure 23: $V=2.8 \mathrm{~m} / \mathrm{s}$. Variation diagram of transverse vibration intensity. (a) First-order. (b) Second-order. (c) Third-order. (d) Fourthorder.

TABLE 6: Vibration data statistics table.

\begin{tabular}{|c|c|c|c|c|c|c|c|}
\hline \multicolumn{4}{|c|}{ Longitudinal } & \multicolumn{4}{|c|}{ Transverse } \\
\hline $\begin{array}{l}\text { Vibration } \\
\text { frequency order } \\
\text { number }\end{array}$ & $\begin{array}{c}c=0 \mathrm{~N} \cdot \mathrm{s} / \mathrm{m} \text {, } \\
\text { vibration } \\
\text { intensity } \\
(\mathrm{dB})\end{array}$ & $\begin{array}{c}c=200 \mathrm{~N} \cdot \mathrm{s} / \mathrm{m}, \\
\text { vibration } \\
\text { intensity }(\mathrm{dB})\end{array}$ & $\begin{array}{l}\text { Attenuation value } \\
\qquad(\mathrm{dB})\end{array}$ & $\begin{array}{c}\text { Vibration } \\
\text { frequency } \\
\text { order } \\
\text { number }\end{array}$ & $\begin{array}{c}c=0 \mathrm{~N} \cdot \mathrm{s} / \mathrm{m} \text {, } \\
\text { vibration } \\
\text { intensity } \\
(\mathrm{dB})\end{array}$ & $\begin{array}{c}c=200 \mathrm{~N} \cdot \mathrm{s} / \mathrm{m} \text {, } \\
\text { vibration } \\
\text { intensity }(\mathrm{dB})\end{array}$ & $\begin{array}{l}\text { Attenuation value } \\
\qquad(\mathrm{dB})\end{array}$ \\
\hline 1 & 15.726 & 13.528 & 2.198 & 1 & 15.626 & 13.442 & 2.184 \\
\hline 2 & 13.173 & 11.459 & 1.714 & 2 & 13.089 & 11.386 & 1.703 \\
\hline 3 & 14.543 & 12.654 & 1.889 & 3 & 14.450 & 12.572 & 1.878 \\
\hline 4 & 13.733 & 11.946 & 1.787 & 4 & 13.646 & 11.870 & 1.776 \\
\hline
\end{tabular}




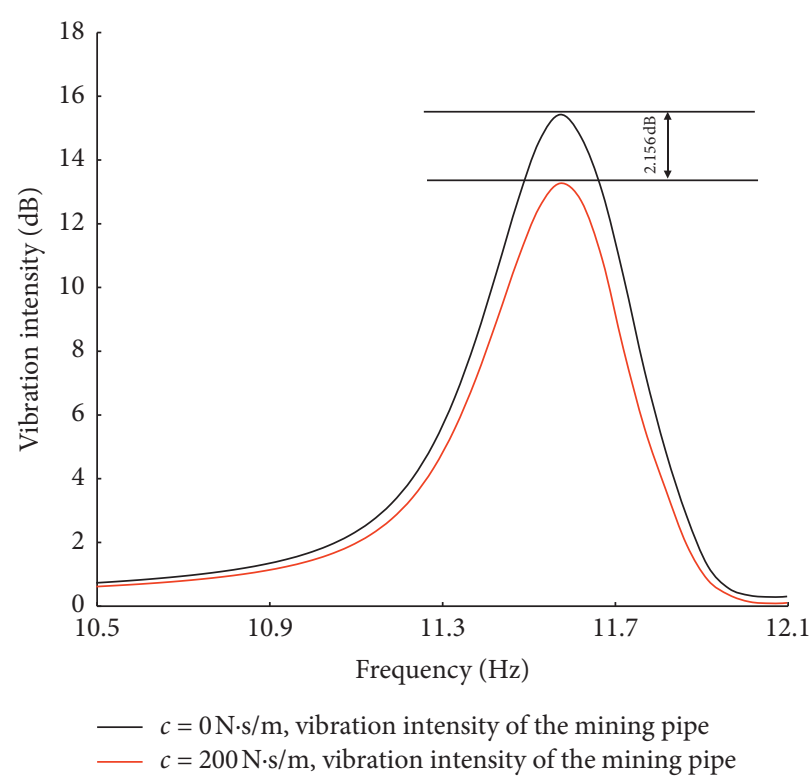

(a)

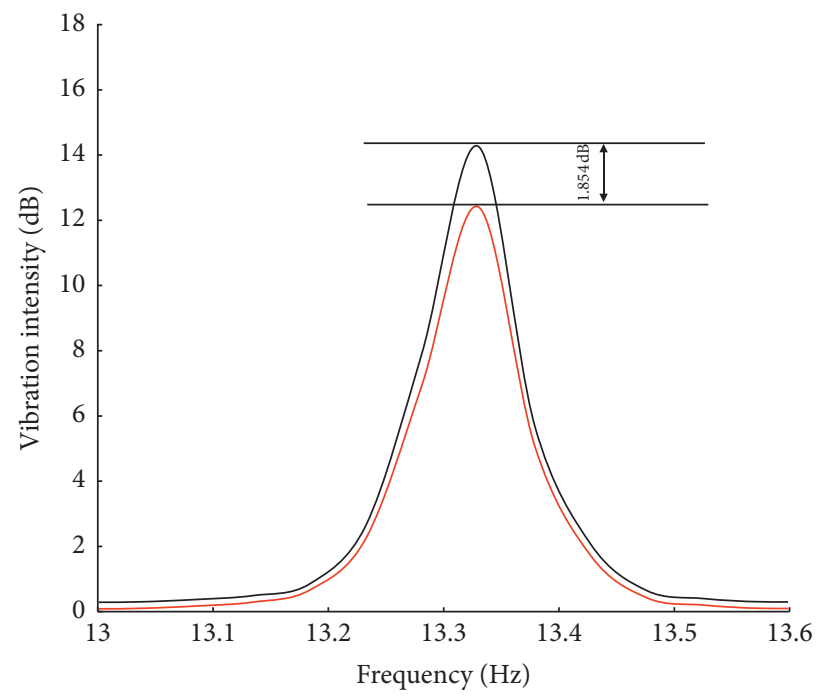

$-c=0 \mathrm{~N} \cdot \mathrm{s} / \mathrm{m}$, vibration intensity of the mining pipe

(c)

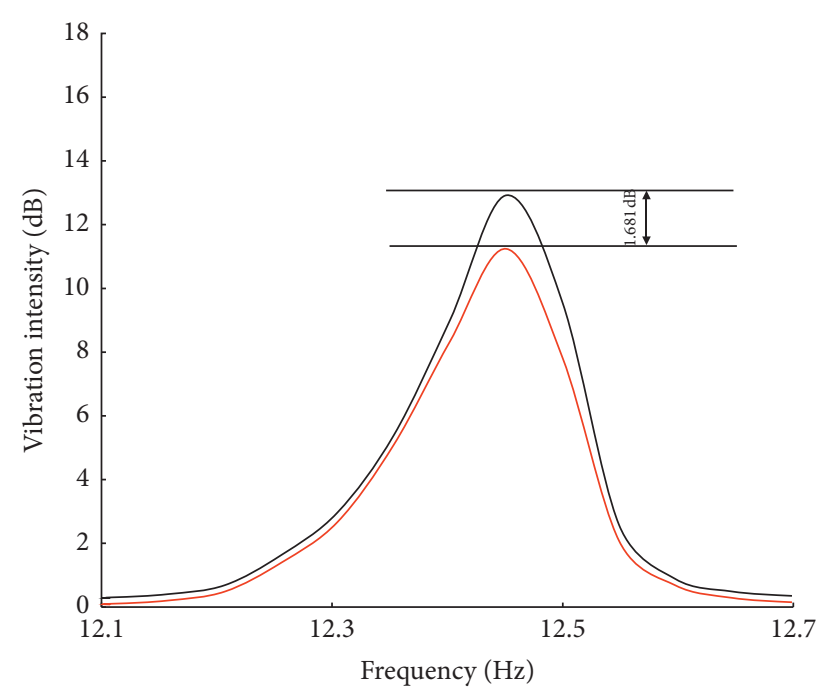

$c=0 \mathrm{~N} \cdot \mathrm{s} / \mathrm{m}$, vibration intensity of the mining pipe $c=200 \mathrm{~N} \cdot \mathrm{s} / \mathrm{m}$, vibration intensity of the mining pipe

(b)

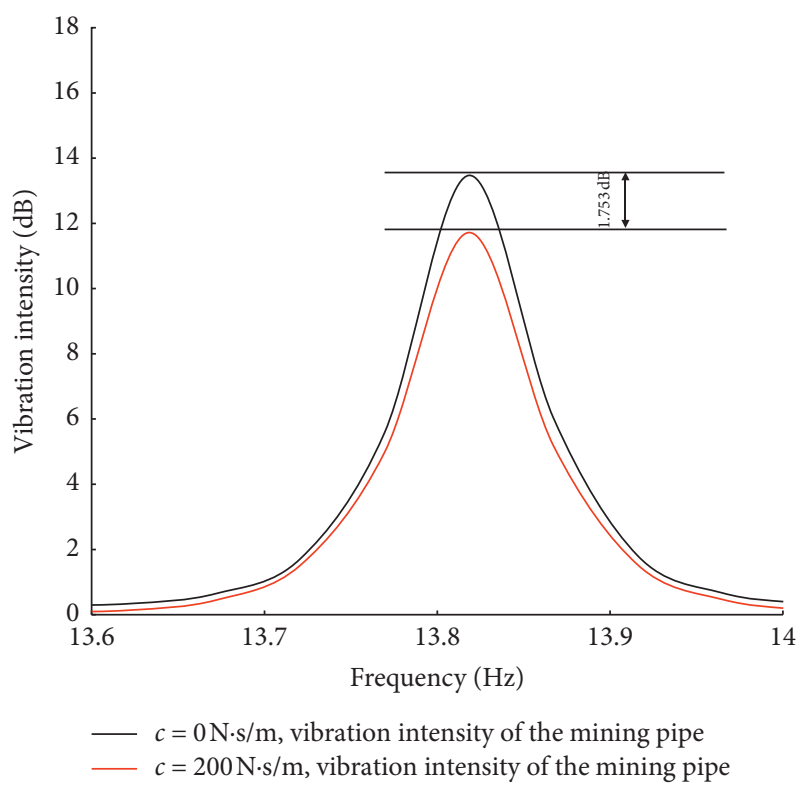

(d)

FIgURE 24: $V=3.0 \mathrm{~m} / \mathrm{s}$. Variation diagram of longitudinal vibration intensity. (a) First-order. (b) Second-order. (c) Third-order. (d) Fourthorder.

Table 7. At this time, the transverse vibration intensity is greater than the longitudinal vibration intensity. When the same damping is added, the attenuation degree of the transverse vibration is greater and the damping effect is more obvious. However, the transverse vibration intensity after adding the damping is still greater than the longitudinal vibration intensity under the same condition, so when the towing velocity is $3.0 \mathrm{~m} / \mathrm{s}$, the vibration reduction 


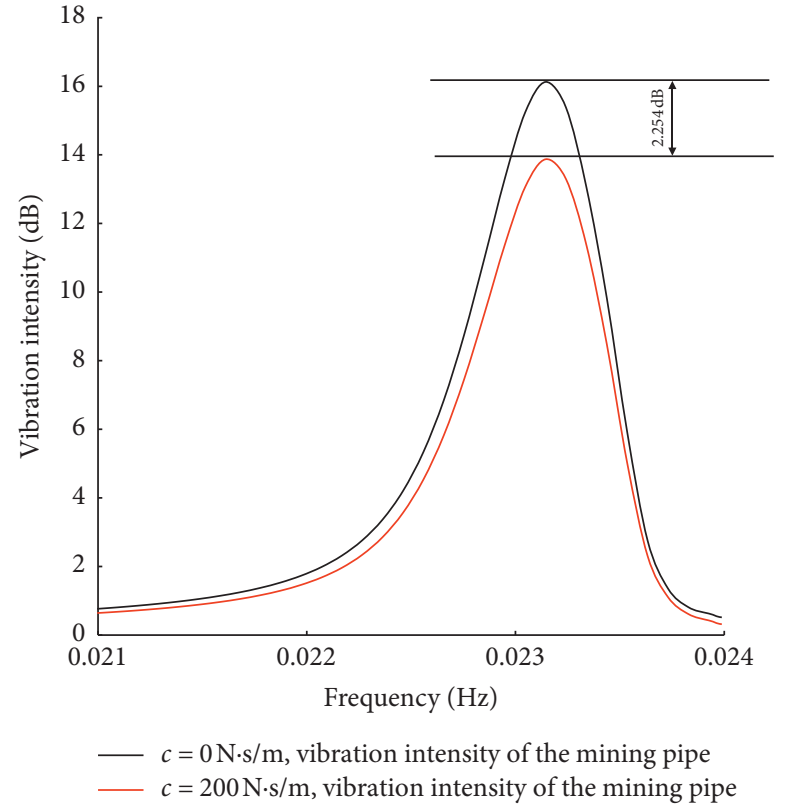

(a)

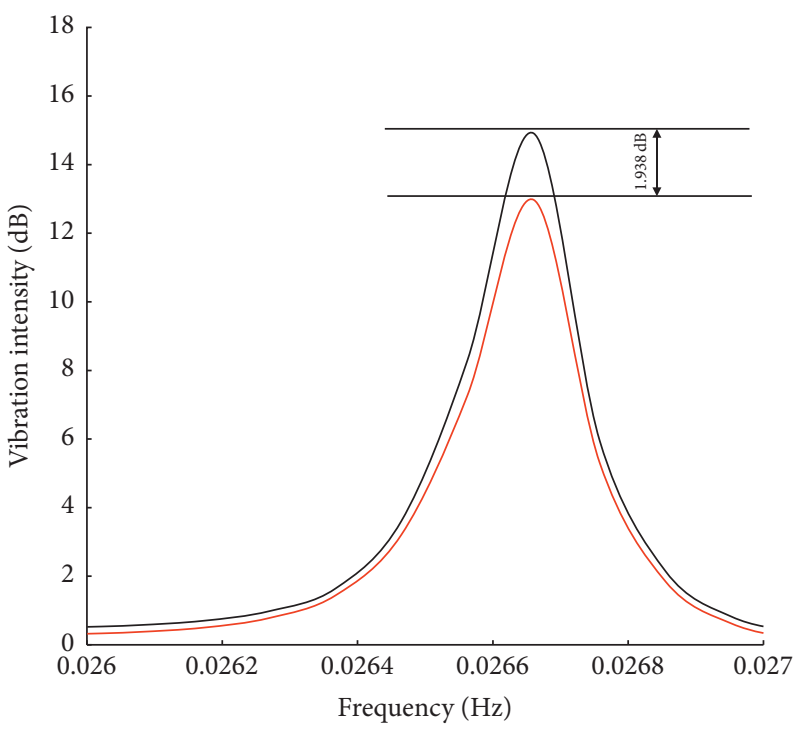

- $c=0 \mathrm{~N} \cdot \mathrm{s} / \mathrm{m}$, vibration intensity of the mining pipe $c=200 \mathrm{~N} \cdot \mathrm{s} / \mathrm{m}$, vibration intensity of the mining pipe

(c)

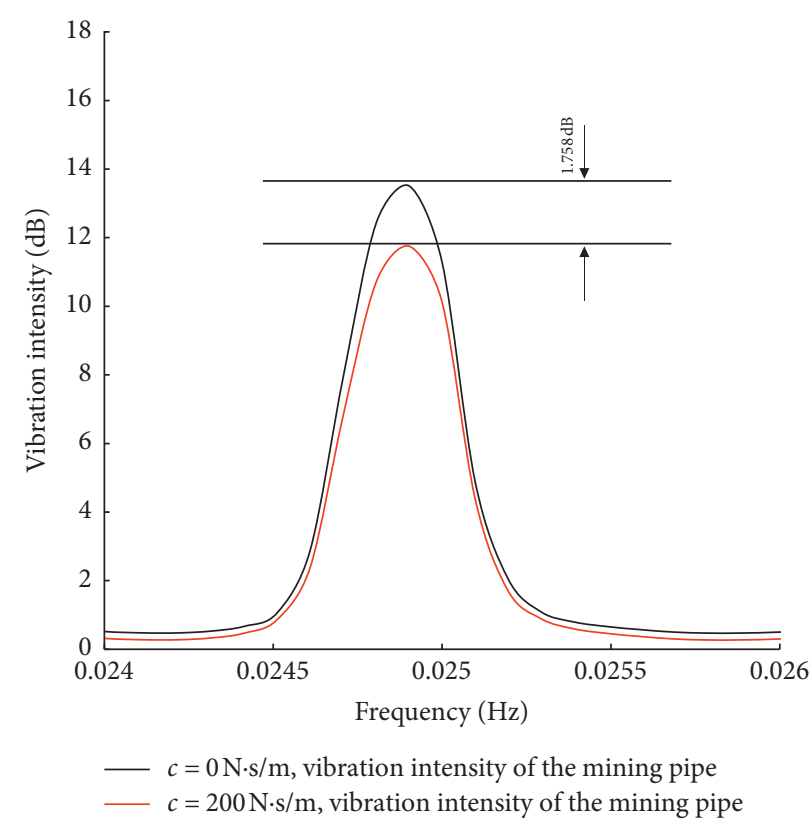

(b)

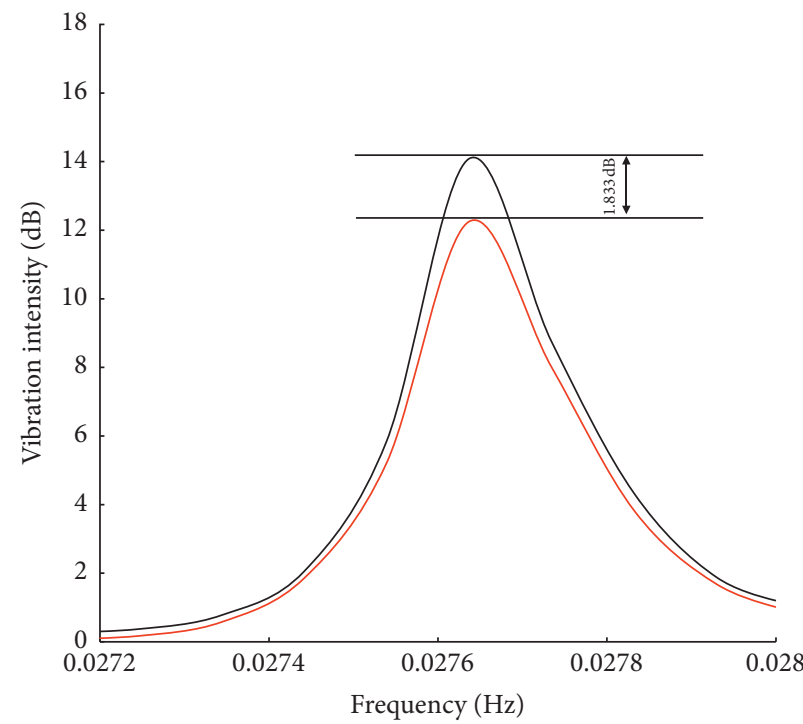

$-c=0 \mathrm{~N} \cdot \mathrm{s} / \mathrm{m}$, vibration intensity of the mining pipe $c=200 \mathrm{~N} \cdot \mathrm{s} / \mathrm{m}$, vibration intensity of the mining pipe

(d)

Figure 25: $V=3.0 \mathrm{~m} / \mathrm{s}$. Variation diagram of transverse vibration intensity. (a) First-order. (b) Second-order. (c) Third-order. (d) Fourthorder.

TABLE 7: Vibration data statistics table.

\begin{tabular}{|c|c|c|c|c|c|c|c|}
\hline \multicolumn{4}{|c|}{ Longitudinal } & \multicolumn{4}{|c|}{ Transverse } \\
\hline $\begin{array}{l}\text { Vibration } \\
\text { frequency order } \\
\text { number }\end{array}$ & $\begin{array}{c}c=0 \mathrm{~N} \cdot \mathrm{s} / \mathrm{m}, \\
\text { vibration } \\
\text { intensity }(\mathrm{dB})\end{array}$ & $\begin{array}{c}c=200 \mathrm{~N} \cdot \mathrm{s} / \mathrm{m}, \\
\text { vibration } \\
\text { intensity }(\mathrm{dB})\end{array}$ & $\begin{array}{l}\text { Attenuation value } \\
\qquad(\mathrm{dB})\end{array}$ & $\begin{array}{l}\text { Vibration } \\
\text { frequency } \\
\text { order } \\
\text { number }\end{array}$ & $\begin{array}{c}c=0 \mathrm{~N} \cdot \mathrm{s} / \mathrm{m}, \\
\text { vibration } \\
\text { intensity }(\mathrm{dB})\end{array}$ & $\begin{array}{l}c=200 \mathrm{~N} \cdot \mathrm{s} / \mathrm{m}, \\
\text { vibration } \\
\text { intensity }(\mathrm{dB})\end{array}$ & $\begin{array}{l}\text { Attenuation value } \\
\qquad(\mathrm{dB})\end{array}$ \\
\hline 1 & 15.425 & 13.269 & 2.156 & 1 & 16.127 & 13.873 & 2.254 \\
\hline 2 & 12.921 & 11.240 & 1.681 & 2 & 13.509 & 11.751 & 1.758 \\
\hline 3 & 14.262 & 12.408 & 1.854 & 3 & 14.913 & 12.975 & 1.938 \\
\hline 4 & 13.471 & 11.718 & 1.753 & 4 & 14.083 & 12.250 & 1.833 \\
\hline
\end{tabular}


control of the transverse vibration should be appropriately increased during the vibration reduction work.

\section{Conclusions}

In this study, the $5000 \mathrm{~m}$ stepped mining pipe is taken as the research object; under the level 6 working wind condition, the mining pipe longitudinal and transverse vibration characteristics are studied, respectively; the main conclusions can be summarised as follows:

(1) The longitudinal and transverse vibration response is irregular motion, and the oscillation phenomenon is obvious, the overall vibration trend decreases first and then increases from the top to the bottom, and the maximum vibration amplitude occurs at the pipe top.

(2) When the ore bin weight, the length of the pipe each step section, and damping are constant, increasing the towing velocity can reduce the longitudinal vibration amplitude and increase the transverse vibration amplitude, but changing the towing velocity will not change the pipe vibration law which decreases first and then increases, nor will it change the position where the minimum vibration occurs.

(3) When the external conditions are stable, increasing the ore bin weight will increase the overall longitudinal vibration amplitude and reduce the overall transverse vibration amplitude. Similarly, changing the ore bin weight will not change the mining pipe vibration law. Increasing the length of the large diameter step section (L1) will simultaneously reduce the longitudinal and transverse vibration amplitude.

(4) When the total length of the mining pipe remains unchanged, the length of the each step section is changed, not only the amplitude of transverse and longitudinal vibration intensity but also the vibration frequency will be changed.

(5) When the external conditions are stable, the towing velocity is between $0-2.8 \mathrm{~m} / \mathrm{s}$, the longitudinal vibration is the main vibration mode, and the intensity of longitudinal vibration is much greater than that of transverse vibration. When the towing velocity reaches $2.8 \mathrm{~m} / \mathrm{s}$, the longitudinal and transverse vibration intensity is the same, and the damping effect is the same after adding damping. When the towing velocity is greater than $2.8 \mathrm{~m} / \mathrm{s}$, the transverse vibration is gradually greater than the longitudinal vibration, and at this time, the vibration reduction control of the transverse vibration should be emphasized.

\section{Data Availability}

The data that support the findings of this study are available from the corresponding author upon reasonable request.

\section{Conflicts of Interest}

The authors declare that there are no conflicts of interest.

\section{Acknowledgments}

This work was supported by the National Natural Science Foundation of China (Allotment Grant no. 51774193) and Shandong Provincial Natural Science Foundation, China (Allotment Grant no. ZR2017MEE025).

\section{References}

[1] H. H. Shi, "The configuration design of composite cable operation and linkage control in polymetallic nodule mining system," Master's thesis, Xiangtan University, Xiangtan, China, 2018.

[2] Y. Peng, "Experimental study on conveying characteristics of coarse grain ore in flexible pipe of the deep sea mining system," Master's thesis, Minzu University of China, Beijing, China, 2016.

[3] Y. Fu, "Study on flexible pipe conveying characteristics in the deep sea mining," Master's thesis, Minzu University of China, Beijing, China, 2019.

[4] Y. Deng, "Software design of spatial configuration and dynamic analysis of flexible pipeline in deep-sea mining system," Master's thesis, Xiangtan University, Xiangtan, China, 2017.

[5] Y.-L. Feng, Y. Xu, F.-Z. Feng, and W. M. Zhang, "Experimental study for lateral motion of $1 \mathrm{~km}$ articulated lifting subsystem," Journal of China University of Mining \& Technology, vol. 36, pp. 246-250, 2007.

[6] W. Song, "Mechanical analysis and design of the mining machine in deep sea mining," Master's thesis, Southwest Petroleum University, Chengdu, China, 2018.

[7] B. R. Cheng and J. S. Chung, "Effects of axial dampers and elastic joints on the 3-D dynamic responses of a deep-ocean pipe with torsional coupling," International Journal of Offshore and Polar Engineering, vol. 7, pp. 36-43, 1997.

[8] J. S. Chung and B. Cheng, "MSE and FEM modeling of thrusts to elastic joints of long vertical pipe in 3-D nonlinear motions," Journal of Energy Resources Technology, vol. 2, pp. 117-125, 1999.

[9] E. H. Achouyab and B. Bahrar, "Numerical modeling of phenomena of waterhammer using a model of fluid-structure interaction," Comptes Rendus Mecanique, vol. 339, no. 4, pp. 262-269, 2011.

[10] S. Hong, H. Kim, and J. Choi, "A new method using Euler parameters for 3D nonlinear analysis of marine risers/pipelines," in Proceedings of the ISOPE Ocean Mining Symposium, Tsukuba, Japan, 2003.

[11] E. Haluk, "Vibration analysis of stepped-pipe strings for mining from deep-sea floors," Ocean Engineering, vol. 32, pp. 37-55, 2005.

[12] C. Mannini, "Incorporation of turbulence in a nonlinear wake-oscillator model for the prediction of unsteady galloping response," Journal of Wind Engineering and Industrial Aerodynamics, vol. 200, Article ID 104141, 2020.

[13] C. Mannini, A. M. Marra, T. Massai, and G. Bartoli, "Interference of vortex-induced vibration and transverse galloping for a rectangular cylinder," Journal of Fluids and Structures, vol. 66, pp. 403-423, 2016.

[14] Q. Wu, J. M. Yang, and H. N. Lu, "Effects of heave motion on the dynamic performance of vertical transport system for 
deep sea mining," Applied Ocean Research, vol. 101, pp. 1-11, 2020.

[15] Y. Li, K. F. Liao, F. Lu, and S. J. Liu, "Dynamic analysis of $1000 \mathrm{~m}$ deep-ocean lifting pipes considering fluid-structure interaction," Journal of Water Resources and Water Engineering, vol. 28, pp. 163-168, 2017.

[16] H. L. Xu, X. Rao, and F. Q. Yang, "Influence of lateral swing on transportation characteristics of deep sea mining pipeline," Journal of Central South University (Science and Technology), vol. 50, pp. 2395-2402, 2019.

[17] X. Y. Qiu, "Research for passive control for longitudinal vibration of lifting pipe in deep sea mining system," Doctoral thesis, Central South University, Changsha, China, 2014.

[18] L. J. Xiao, Q. Liu, and B. Liang, "Longitudinal vibration analysis of hoisting pipe in deep-sea mining based on combination action of wave and current," Mining Research and Development, vol. 39, pp. 147-150, 2019.

[19] L. J. Li, "Study on design and control of active heave compensation system of deep sea mining based on dynamic vibration absorber," Doctoral thesis, Central South University, Changsha, China, 2012.

[20] L. J. Xiao, S. Zuo, and Q. H. Song, "Analysis on static characteristics of lifting pipe in deep sea mining," Mining Research and Development, vol. 40, pp. 130-135, 2020.

[21] L. Liu, "Research on dynamic performance of solid-liquid two-phase flow in hydraulic transport in deep sea mining," Master's thesis, Shanghai Jiao Tong University, Shanghai, China, 2019.

[22] Y. Li, G. C. Jia, and S. J. Liu, "Mechanical characteristics on long lifting pipeline in deep-ocean mining considering fluidstructure interaction," Journal of Central South University (Science and Technology), vol. 47, pp. 3670-3676, 2016.

[23] Q. Liu and L. Xiao, "Analysis and research on longitudinal vibration characteristics of deep sea mining pipe based on finite element method," Mathematical Problems in Engineering, vol. 2020, Article ID 8219794, 18 pages, 2020.

[24] B. Liang, J. L. Xu, and T. W. Zhai, "Finite element analysis of longitudinal vibration of hoisting pipe in deep sea mining," Mining Research and Development, vol. 39, pp. 106-109, 2019.

[25] L. J. Xiao, S. Zuo, and Z. H. Yu, "Longitudinal vibrations analysis of lifting pipe in deep-sea mining," Science Technology and Engineering, vol. 20, pp. 7213-7219, 2020.

[26] B. Xu, Y. F. Gao, and L. Yu, MATLAB Finite Element Structural Dynamics Analysis and Engineering Application, Tsinghua University Press, Beijing, China, 2009.

[27] P. Zeng, Finite Element Basic Course, Higher Education Press, Beijing, China, 2017.

[28] B. Liang, "Study on longitudinal vibration and vibration reduction of uplift tube in deep sea mining," Master's thesis, Shandong University of Science and Technology, Qingdao, China, 2019.

[29] S. Zuo, "Longitudinal vibration analysis of the uplift pipe in deep sea mining," Master's thesis, Shandong University of Science and Technology, Qingdao, China, 2020.

[30] S. Q. Wang and B. C. Ling, Ocean Engineering Wave Mechanics, Ocean University of China Press, Qingdao, China, 2013.

[31] G. Wang, "Research on spatial configuration and dynamic characteristics of hoisting pipeline system in deep-sea mining operations," Doctoral thesis, Central South University, Changsha, China, 2009.

[32] X.Z. Hu, "Dynamic analysis of hydrodynamic problems of main components of $1000 \mathrm{~m}$ ocean pilot mining system in deploying process," Doctoral thesis, Central South University, Changsha, China, 2011.

[33] H. W. Liu, Mechanics of Materials, Higher Education Press, Beijing, China, 2011.

[34] T. C. Feng, Ship Swaying \& Manipulating, National Defense Industry Press, Beijing, China, 1989.

[35] X. C. Wang, Finite Element Method, Tsinghua University Press, Beijing, China, 2015.

[36] R. Q. Xu, Finite Element Method of Structural Analysis and MATLAB Program Design, China Communications Press, Beijing, China, 2006.

[37] M. A. Li, MATLAB/SIMULINK Dynamics System Modeling and Simulation, National Defense Industry Press, Beijing, China, 2015.

[38] L. Xiao, Q. L. Zeng, and W. M. Zhang, "Analysis of nonlinear offsetting characteristics on deep ocean mining pipe," Chinese Journal of Mechanical Engineering, vol. 38, no. 8, pp. 94-99, 2002.

[39] L. J. Xiao, "Study on kinematics and dynamics characteristics of the deep sea mining pipe," Doctoral thesis, University of Science and Technology Beijing, Beijing, China, 2000.

[40] Y. X. Cheng, N. Yang, and X. Jin, "Simulation of flexible multibody dynamics for deep-sea lifting system," Mining and Metallurgical Engineering, vol. 34, pp. 6-9, 2014.

[41] N. Q. Hu, Mechanical Vibration, National University of Defense Technology Press, Changsha, China, 2017. 